\title{
ATOMIC SPECTROMETRY UPDATE: REVIEW OF ADVANCES IN ATOMIC SPECTROMETRY AND RELATED TECHNIQUES
}

\section{E. Hywel Evans ${ }^{* a}$, Matthew Horstwood ${ }^{b}$, Jorge Pisonero ${ }^{c}$ and Clare M. M. Smith ${ }^{\text {d }}$}

a School of Geography, Earth, and Environmental Sciences, University of Plymouth, Drake Circus, Plymouth, UK PL4 8AA

${ }^{\mathrm{b}}$ British Geological Survey, Keyworth, Nottingham, NG12 5GG

${ }^{c}$ University of Oviedo, Faculty of Science, Department of Physics, c/ Calvo Sotelo s/n, 33006 Oviedo, Spain

${ }^{\mathrm{d}}$ St. Ambrose High School, Blair Road, Coatbridge, Lanarkshire, UK ML5 2EW

\section{SUMMARY OF CONTENTS}

This review covers developments in 'Atomic Spectrometry'. It covers atomic emission, absorption, fluorescence and mass spectrometry, but excludes material on speciation and coupled techniques which is included in a separate review. It should be read in conjunction with the other related reviews in the series. ${ }^{1-6}$ A critical approach to the selection of material has been adopted, with only novel developments in instrumentation, techniques and methodology being included. Developments worthy of note include photochemical and electrochemical methods of vapour generation, single particle analysis using ICP-MS and the development of new methods for direct plasma generation in liquid samples. The use of MCICP-MS continues to grow in importance for isotope ratio measurements in fields as diverse as geochronology, nuclear forensics and biomedical research. Laser-based methods are also important in many fields, particularly for direct and stand-off analysis of solid samples.

\section{Sample introduction}

\subsection{Liquids}

\subsubsection{Sample pre-treatment.}

\subsubsection{Solid Phase Extraction}

\subsubsection{Liquid-liquid extraction}

\subsubsection{Metal tagging}

\subsubsection{Automated methods}

\subsubsection{Miscellaneous}




\subsubsection{Nebulization}

1.1.2.1 Single particle analysis

1.1.2.2. Nebulizers

1.1.3 Thermal vaporization

1.2 Vapour generation

1.2.1 Chemical Vapour Generation.

1.2.2 Electrochemical Vapour Generation

1.2.3 Photochemical Vapour Generation

1.3 Solids

1.3.1 Direct methods.

1.3.1.1 Arc \& spark

1.3.1.2 Secondary ion mass spectrometry

2 Instrumentation, Fundamentals and Chemometrics

2.1 Instrumentation

2.2 Fundamentals

2.3 Chemometrics

3 Laser-based Atomic Spectrometry

3.1 Lasers as energy sources

3.1.1. Laser induced breakdown spectroscopy (LIBS)

3.1.1.1 Fundamental Studies

3.1.1.2 Instrumentation

3.2 Lasers as sources of intense monochromatic radiation

3.2.1 Laser atomic absorption

3.2.2 Cavity Ringdown Spectroscopy (CRDS).

3.2.3 Laser-induced fluorescence (LIF).

4 Isotope Analysis

4.1 Instrumentation.

4.2 Sample preparation

4.3 New applied developments

4.3.1 Nuclear forensics

4.3.2 Geochronology 


\title{
4.3.3 Environmental and bioanalytical science
}

\author{
5 Glossary of Abbreviations
}

\section{References}

\section{Sample introduction}

This section covers developments in sample introduction for all instrumental methods.

\subsection{Liquids}

Liquid sample introduction relates to methods wherein the sample is introduced into the instrument in the form of a liquid, such as through nebulization or into a thermal vaporizer; whereas in vapour generation the sample is initially in the form of a liquid but is converted to a vapour prior to introduction into the instrument.

\subsubsection{Sample pre-treatment.}

A general review of on-line preconcentration for ICP-MS has been published by Das et al. ${ }^{7}$, covering solid phase methods and including 63 references. Several reviews of sample pretreatment methods used for atomic spectrometry are worth noting because they focus on specific areas: Kocurova et al. ${ }^{8}$ and Jain and Verma ${ }^{9}$ have reviewed advances in DLLME (53 references) and SDME (407 references) respectively; Zhao et al. ${ }^{10}$ have reviewed (151 references) chromium preconcentration methods; Pyrznska ${ }^{11}$ has reviewed gold preconcentration; and Mesko et al. ${ }^{12}$ have reviewed methods of sample preparation (including preconcentration and derivatization) for metalloid or metalloid-containing biomolecules over the preceding fifteen years (157 references).

1.1.1.1 Solid Phase Extraction. Several extraction/pre-concentration techniques which have come to prominence over the last few years have been adapted from methods used in other areas of analytical chemistry. One of these is the use of magnetic particles (recently rebadged as nano-particles) which have been widely used in immunoassays. These are $\mathrm{Fe}_{3} \mathrm{O}_{4}$ particles which have been functionalized with an adsorbent organic molecule for chelation of a target element from solution. The advantage of this approach is that the magnetic particles can then be easily separated from the aqueous phase by application of a magnetic field. A 
reasonable number of papers appear each year which describe applications of this approach using chelating dyes and other preconcentration media, however, very little of novelty has been reported. One paper of note, by Wang et al., ${ }^{13}$ describes the combination of magnetic particles functionalized with sodium dodecyl sulphate, a lab-on-a-valve system and ETAAS in an automated system, for the determination of Co in waters, with an LOD of $6 \mathrm{ng} \mathrm{L}^{-1}$ and $2.8 \%$ RSD.

Ion imprinted polymers have attracted much interest as selective SPE media for metal ions. Zhang and $\mathrm{Hu}^{14}$ have developed a stir-bar which can be used for extraction of $\mathrm{Cd}^{\mathrm{II}}$ from waters by coating a glass bar successively with tetramethoxysilane, then 3mercaptopropyltrimethoxysilane and $\mathrm{Cd}^{\mathrm{II}}$ micelles with acetyltrimethyllammonium bromide as the template. Under optimized conditions the adsorption capacities of non-imprinted and imprinted bars were 0.5 and $0.8 \mu \mathrm{g}$ respectively, with an LOD of $4.4 \mathrm{ng} \mathrm{L}^{-1}$ achieved using ICP-MS. This does not seem to suggest a create deal of selectivity, and indeed $\mathrm{Cu}$ and $\mathrm{Ni}$ were co-extracted, however, the authors reported successful analysis of a river water CRM. In comparison, Tsoi et al. ${ }^{15}$ have reported a 25 -fold enhancement in the adsorption capacity of an As imprinted polymer based on 1-vinylimidazole compared to a non-imprinted polymer, with an LOD of $0.025 \mu \mathrm{mol} \mathrm{L}{ }^{-1}$ using ICP-MS detection.

Shamaeli and Alizadeh have reported ${ }^{16}$ the use of the conducting polymer polypyrrole as a novel method of SPE. A stainless steel electrode is coated with the polymer and doped with erichrome blue dye such that the cation complexing properties of the dye can be switched on and off by altering the potential on the electrode. Electrochemically switched cation exchange of $\mathrm{Ni}^{\mathrm{iI}}$ was completed within $250 \mathrm{~s}$.

The use of natural materials for SPE, so called biosorption, has come to the fore in recent years. Pacheco et al. ${ }^{17}$ have published a review (148 references) covering research since 2000. Two separate papers by the same research group have appeared ${ }^{18,19}$ which report the use of eggshell membrane for SPE of Au and Ag from geological samples, using ICP-MS and FAAS detection respectively. Extraction of $\mathrm{Au}$ was performed in $1.2 \mathrm{~mol} \mathrm{~L}^{-1} \mathrm{HCl}$ and eluted in a $1 \%$ thiourea $+0.12 \mathrm{~mol} \mathrm{~L}^{-1} \mathrm{HCl}$ mixture, whereas Ag was extracted from $0.4 \mathrm{~mol} \mathrm{~L}^{-1}$ $\mathrm{HNO}_{3}$. The authors claim that transition and heavy metals did not interfere and obtained an LOD of $0.92 \mathrm{ng} \mathrm{L}^{-1}$ for Au using ICP-MS and good agreement with HGAAS for the analysis of water CRMs was obtained. 
Electrochemical preconcentration is a technique which periodically offers new promise. Cacho et al. ${ }^{20}$ pre-concentrated As from water samples using a gold-plated, microporous carbon electrode by electrodeposition from $\mathrm{HCl}$ solution and stripping into $60 \mu \mathrm{L}$ of $\mathrm{HNO}_{3}$. Detection using ETAAS yielded an LOD of $0.004 \mu \mathrm{g} \mathrm{L^{-1 }}$.

1.1.1.2 Liquid-liquid extraction. Liquid-liquid extraction methods have been around for a long time so there are few novel developments. However, the use of ionic liquids for LLE has recently attracted some interest. Vickackaite and Padaruskas ${ }^{21}$ have reviewed the application of ionic liquids in analytical chemistry (118 references) and their compatibility with a range of instrumental techniques. Likewise, Joshi and Anderson have reviewed the use of ILs in separation science and mass spectrometry (219 references). ${ }^{22}$ Advantages of ionic liquids include low vapour pressure, high conductivity and solvating properties, and they are often cited as a replacement for organic solvents. However, LLE methods often require that they be used in conjunction with a chelating agent to improve specificity for the target analyte(s). For example, Ranjbar et $a .^{23}$ have used 1-hexyl-3-methyl-imidazolium bis(trifluoromethylsulfonyl)imide in conjunction with 1-(2-theonyl)-3,3,3-trifluoroacetone for microextraction of $\mathrm{Co}^{\mathrm{II}}, \mathrm{Cu}^{\mathrm{II}}, \mathrm{Mn}^{\mathrm{II}}, \mathrm{Ni}^{\mathrm{II}}$ and $\mathrm{Zn}^{\mathrm{II}}$ from water samples and detection using ICPAES. They optimised the $\mathrm{pH}$, ionic strength and relative amounts of the reagents using a halffactorial design and achieved LODs between 0.1-0.2 $\mathrm{ng} \mathrm{mL} \mathrm{mL}^{-1}$ which equated to preconcentration factors of c.a. 100. Berton et al. ${ }^{24}$ used ultrasound to enhance extraction using 1-hexyl-3-methylimidazolium hexafluorophosphate $\left(\mathrm{C}_{6}-\mathrm{mim}-\mathrm{PF}_{6}\right)$ after chelation of $\mathrm{Co}^{\mathrm{II}}$ with 1-nitroso-2-naphtol. They optimised the $\mathrm{pH}$ to improve the selectivity of extraction of Co from nutritional supplements, and dissolved the final IL phase in methanol prior to detection using ETAAS, achieving an LOD of $5.4 \mathrm{ng} \mathrm{L}^{-1}$. Two reports describe the use of ILs for the extraction of $\mathrm{Ag}^{\mathrm{I}}$. The first $^{25}$ described the use of 1-butyl-3-methylimidazolium hexafluorophosphate $\left(\mathrm{C}_{4}-\mathrm{mim}-\mathrm{PF}_{6}\right)$ and the chelator 5-(4-dimethylaminobenzylidene)rhodanine, back-extraction into thiosulphate solution and FAAS detection, with an LOD of $0.28 \mathrm{ng} \mathrm{mL}^{-1}$. Satisfactory results were obtained for the analysis of environmental CRMs. The second ${ }^{26}$ reported the use of tetraethylthiuram disulfide dissolved in $\mathrm{C}_{6}-\mathrm{mim}-\mathrm{PF}_{6}$ as the extracting IL for the determination of $\mathrm{Ag}^{\mathrm{I}}$ in drinking water and hair samples using ETAAS detection. Optimisation of the various parameters resulted in RSD, LOD and preconcentration factor of $4.5 \%, 5.3 \mathrm{ng} \mathrm{L}^{-1}$ and 120 respectively. Martinis et al. ${ }^{27}$ have 
developed an IL extraction method, coupled with a SPE microcolumn and ETAAS, for the determination of $\mathrm{Se}^{\mathrm{IV}}$ in garlic extracts and water samples. They used a chelating agent to form a Se-APDC complex followed by extraction with tetradecyl(trihexyl)phosphonium chloride, then SPE extraction on the microcolumn. The method was selective for $\mathrm{Se}^{\mathrm{IV}}$, but $\mathrm{Se}^{\mathrm{VI}}$ could also be detected after reduction, and the LOD was $15 \mathrm{ng} \mathrm{L}^{-1}$.

1.1.1.3 Metal tagging. The use of metal tags to visualise bio-organic molecules for detection using atomic spectrometry has generated considerable interest due to the inherently high selectivity and sensitivity of atomic spectrometry. Iwahata et al. ${ }^{28}$ have taken advantage of this to determine the branched amino acids in a single fruit fly $D$. melanogaster by derivatizing with a six-coordinated ruthenium complex, bis(2,2'-bipyridine)-4'-methyl-4carboxybipyridine-ruthenium $N$-succinimidyl ester-bis(hexafluorophosphate), separation with LC and detection using ICP-MS, thus allowing an 'aminogram' to be obtained for a single adult fly, the larva and the pupa. A similar approach has been reported by Tang et al. ${ }^{29}$ who determined total urinary protein by bio-conjugation with CdTe quantum dots in a micro-titre plate The conjugates were diluted to $4 \mathrm{~mL}$ with $1 \%(\mathrm{v} / \mathrm{v})$ nitric acid and analysed using ICPMS with an LOD of $8 \mathrm{ng} \mathrm{mL} \mathrm{mL}^{-1}$. A number of methods involving metal tags have been developed using reagents normally used for fluorescence tagging. Kretschy et al. ${ }^{30,31}$ have used organo-lanthanide fluorescent tags to determine bio-molecules such as peptides using ICP-MS detection. In the first study ${ }^{30}$ they quantified the peptide $\mathrm{B} \beta_{15-42}$ in fractioned cell samples of human umbilical cord vein endothelial cells by labelling with 4,7,10tetraazacyclododecane- $\mathrm{N}, \mathrm{N}^{\prime}, \mathrm{N}^{\prime \prime}, \mathrm{N}^{\prime \prime \prime}$-tetraacetic acid (In-DOTA) and 2-(4isothiocyanatobenzyl)-1,4,7,10-tetraazacyclododecane-N, $\mathrm{N}^{\prime}, \mathrm{N}^{\prime \prime}, \mathrm{N}^{\prime \prime \prime}$-tetraacetic acid (InDOTA-Bn), and using FI-SF-ICP-MS for detection of the In part of the label. They achieved an LOD of $9 \mathrm{pM}$, compared to $100 \mathrm{pM}$ with fluorescence detection, and also reported improved precision of $0.3-3.3 \%$. In the second paper $^{31}$ the same authors studied the stability of the labelled complexes at different $\mathrm{pH}$ and temperature, and when subject to separation using LC. They reported a significant decrease in stability when LC separation was used, and some degradation at $37^{\circ} \mathrm{C}$ compared to $2{ }^{\circ} \mathrm{C}$.

Li et $a{ }^{32}$ have developed an interesting indirect method for the determination of DNA sequences containing a single base mis-match. They used a single stranded DNA probe which was complexed with $\mathrm{Hg}^{2+}$ via the thymine bases on the DNA (ssDNA-Hg). On 
exposure to the target DNA sequence, the ssDNA-Hg complex bound with the target DNA releasing $\mathrm{Hg}$ into solution, which was then determined using CE-ICP-MS with an LOD of 8 nmol L ${ }^{-1}$.

An immunoassay-linked method using gold nano-particles has been developed by Jarujamrus et $a .^{33}$. In this approach the monoclonal antibody-chloramphenicol was attached to a solid support. Antigen-chloramphenicol was labelled with gold nano-particles $(10 \mathrm{~nm})$ at $\mathrm{pH}$ 9.5, attached to a bovine serum albumin protein and mixed with unlabelled antigenchloramphenicol, which was then added to the antibody-chloramphenicol. Chloramphenicol was indirectly determined by detection of the uncomplexed gold-labelled antigen using ICPMS in a classical immunoassay approach, with LOD of $5 \mathrm{ng} \mathrm{mL}$.

1.1.1.4 Automated methods. Automation of sample preparation has long been a favourite of researchers looking to utilise the versatility and high sample throughput of flow injection coupled with on-line detection, with many manufacturers offering optional accessories under computer control. One development of note is the miniaturized lab-on-a-valve (LOV) system which has been reviewed by Yu et al. ${ }^{34}$ (53 references). Rodriguez et al. ${ }^{35}$ have used a LOV system for the solid-phase separation and preconcentration of total and radioactive $\mathrm{Sr}$ in environmental samples by ICP-AES and proportional counting, with LODs of $1.8 \mathrm{ng}$ and $0.008 \mathrm{~Bq}$ respectively. An on-line system for the in vivo analysis of microdiasylate extracted directly from the intracellular fluid of a living rat brain has been developed ${ }^{36}$. In this system the microdiasylate was extracted into $0.9 \% \mathrm{NaCl}$ at $\mathrm{pH} 7.4$ through a $20 \mathrm{kDa}$ membrane at a perfusion rate of $1 \mu \mathrm{L} \mathrm{min}{ }^{-1}$ for $600 \mathrm{~s}$, after which the metal ions were separated onto a nonfunctionalized PTFE tube, in-line with various injection valves under computer control. The analyte was eluted in $0.5 \% \mathrm{HNO}_{3}$ and analysed using ICP-MS to achieve an LOD of between $0.003-0.5 \mu \mathrm{g} \mathrm{L}^{-1}$ for $\mathrm{Mn}, \mathrm{Ni}$ and $\mathrm{Zn}$. Avivar et al. ${ }^{37}$ have used LOV-ICP-MS in combination with SPE for the determination of Th and $\mathrm{U}$ in environmental samples. The use of a multisyringe system and separation on UTEVA resin allowed the whole process to be automated, with an injection frequency of $9 \mathrm{~h}^{-1}$ and LODs of 0.4 and $2.8 \mathrm{ng} \mathrm{L}^{-1}$ for $\mathrm{U}$ and Th respectively in water samples.

1.1.1.5 Miscellaneous. A microelectrochemical flow cell has been coupled with ICP-MS by Klemm et al. ${ }^{38,39}$. In the first paper $^{38}$ they report its use for the determination of the valence of $\mathrm{Cu}$ ions released during anodic dissolution in to $\mathrm{HCl}$, with ICP-MS acting as the means of 
quantitation. They extended this to the analysis of polycrystalline $\mathrm{Rh}$ in $0.1 \mathrm{M} \mathrm{H}_{2} \mathrm{SO}_{4}$ to quantitatively determine dissolution rates during various electrochemical treatments.

Sanchez et al. ${ }^{40}$ used a single-pass spray chamber heated to $350{ }^{\circ} \mathrm{C}$ in conjunction with FI-ICP-AES for the determination of metals in petroleum products in small sample volumes of $5 \mu \mathrm{L}$ or less. The advantage of this simple approach is that the sample introduction efficiency approached $100 \%$, but the small sample volume meant that the plasma tolerated such volatile samples as gasoline, superethanol, and diesel diluted in xylene. Hence, a single xylene standard could be used as a universal calibrant for the determination of $\mathrm{Cu}, \mathrm{Mn}, \mathrm{Si}$, and $\mathrm{V}$.

\subsubsection{Nebulization}

1.1.2.1 Single particle analysis. There have been several reports on the use of single particle (SP) ICP-MS for the characterization of nano-particles. In this technique, ICP-MS is operated in pulse counting mode with a minimum dwell time and an oscilloscope for rapid data acquisition. Provided the nebulized solution is dilute enough, and the dwell time short enough, then ion signals resulting from individual droplet particles can be resolved, with signal intensities proportional to the size of the particles. Olesik and Gray have investigated these parameters ${ }^{41}$ and produced a set of recommendations as follows: the number of particles entering the plasma per second must be limited to keep the probability of signals from two particles overlapping acceptably low; a high data acquisition rate (10000 to 100000 $\mathrm{Hz}$ ) or dwell time greater than $10 \mathrm{~ms}$ must be used; detector dead time must be optimised for the maximum count rate at the peak of the transient signal for each particle; and the sensitivity depends on the volume sample introduced during the measurement time and the speed of vaporization of the particles. The importance of evaluating transport efficiency is highlighted by Pace et al. ${ }^{42}$ in their 'practical guide' to SP-ICP-MS, who point out that it is important to have an accurate value for this parameter in order to determine particle number concentration and particle size.

Franze et al. ${ }^{43}$ have evaluated three different nebulizers for characterisation of $\mathrm{Ag}$ nanoparticles (Ag-NP) of 20-100 nm size by SP-ICP-MS. The three nebulizer systems were: a PFA micronebulizer with Peltier-cooled cyclonic spray chamber (PC3); a PFA micronebulizer with a heated cyclonic spray chamber and three-stage Peltier-cooled desolvation system (APEXQ); and a monodisperse droplet generator (Microdrop) with a custom spray chamber. Single particles $(20-30 \mathrm{~nm})$ were successfully detected using all three 
systems, with sensitivities in the range $5.8 \times 10^{-5}$ to $1.2 \times 10^{-4}$ counts per atom for the $20-100$ $\mathrm{nm}$ particle sizes. Miltrano et $a{ }^{44}$ have applied the SP-ICP-MS technique to the determination of AgNP in health-food products and wastewater products. In the latter case they reported the determination of Ag-NP at 100 to $200 \mathrm{ng} \mathrm{L}^{-1}$ in the presence of 50 to $500 \mathrm{ng}$ $\mathrm{L}^{-1}$ dissolved Ag.

It is also possible to determine NPs by coupling separation techniques such as FFF, gel electrophoresis and size exclusion chromatography with SP-ICP-MS. Jiminez et al. have given an overview (96 references) of this area. ${ }^{45}$ Miltrano et al. ${ }^{46}$ have compared FFF-ICPMS with SP-ICP-MS for the determination of NPs and found that the latter was more sensitive (ng L ${ }^{-1}$ versus $\mu \mathrm{g} \mathrm{L}^{-1}$ ) than the former, with the added advantages of being able to differentiate between dissolved and NP fractions of a metal withbetter size resolution $(2 \mathrm{~nm}$ versus $20 \mathrm{~nm}$ ). Bolea et al. ${ }^{47}$ have also used FFF-ICP-MS to determine Ag-NPs in consumer products. They optimised the mobile phase composition and operating conditions to prevent particle aggregation, with best results obtained using conditions which favoured charge repulsions within the membrane. An LOD of $5.6 \mu \mathrm{g} \mathrm{L}^{-1}$ for $\mathrm{Ag}$, which corresponds to $1 \times 10^{12}$ Ag-NP L ${ }^{-1}$ for a $10 \mathrm{~nm}$ particle size, was obtained. A novel approach has been adopted by Kapellios and Pergantis, who have reported $^{48}$ using nanoelectrospray ion mobility spectrometry (IMS) with off-line SP-ICP-MS for the determination of $60 \mathrm{~nm}$ (nominal) $\mathrm{Au}-$ NPs. Initial detection with a condensed particle counting detector revealed the presence of 9.1 $\mathrm{nm}$ and $59.6 \mathrm{~nm}$ particles (the former attributed to salt formation) which were then collected and analysed using SP-ICP-Ms to determine the Au content. A slightly different approach to the determination of molecular aggregates has been taken by Umehara et al. ${ }^{49}$, who have coupled wide-bore hydrodynamic chromatography (HDC) with ICP-MS for the detection of lecithin vesicles which have been used to extract lanthanide ions in the presence of other transition metals, the upshot of this being that it has potential for selective extraction of targeted small molecules. Pergantis et al. ${ }^{50}$ have also investigated HDC in combination with ICP-MS operated in SP mode to enable determination of the size, number concentration, and metal content of Au-NPs. Using this approach they achieved an LOD of $2.2 \mathrm{ng} \mathrm{L}^{-1}$ for $60 \mathrm{~nm}$ $\mathrm{Au}-\mathrm{NPs}$, equivalent to $600 \mathrm{Au}-\mathrm{NP} \mathrm{mL}^{-1}$.

1.1.2.2. Nebulizers. There are few new developments in this area, which is unsurprising given that the basic principles have been established for a considerable time. Geertsen et al. ${ }^{51}$ have developed a micro-flow pneumatic nebulizer which is able to operate at $1 \mu \mathrm{L} \mathrm{min}{ }^{-1}$ and 
yield a sensitivity of 40,000 cps for a $1 \mathrm{ppb}$ solution of $U$ when used with ICP-MS. Using this design, based on a commercial glass concentric slurry nebulizer with an axially introduced fused silica capillary $(20 \mu \mathrm{m}, 50 \mu \mathrm{m}, 75 \mu \mathrm{m}$ or $100 \mu \mathrm{m}$ i.d. with a $360 \mu \mathrm{m}$ o.d. $)$, they were able to investigate the effect of various configurations on aerosol characteristics by particle image velocimetry (PIV), shadowgraphy and interferometic laser imaging for droplet sizing (ILIDS). Comparison with previous studies highlighted the importance of the nozzle geometry, specifically 'stick-out' of the fused silica capillary and its internal diameter. In particular, they found that the degree of 'stick-out' affected the velocity distribution of the aerosol and signal stability but not the oxide ratio or droplet size distribution.

Cheng et al. ${ }^{52}$ have developed a microfluidic system for nanolitre sampling based on a microfluidic chip using a demountable capillary microflow nebulizer with a heated, single-pass spray chamber, a negative pressure sampler, a syringe pump and an HV supply. The system combines both electrokinetic and hydrodynamic flow, isolated from each other by porous polymer plugs fabricated into the microchannels, and operated with a sample consumption of $1.8 \mathrm{~nL}$. It was used in combination with ICP-MS to determine Pt in serum at a sample throughput rate of $112 \mathrm{~h}^{-1}$ with an LOD of $64 \mathrm{ng} \mathrm{L}^{-1}$. The same workers have also adapted this system as a suction-free interface for use with microchip electrophoresis (ME) and ICP-MS, ${ }^{53}$ with the two porous polymer plugs acting to reduce suction. Comparable electrophoretic separations compared to the situation without the plugs were obtained. Using a microchip with an effective separation length of $15 \mathrm{~mm}$ at $857 \mathrm{~V} \mathrm{~cm}^{-1}$ using $10 \mathrm{mmol} \mathrm{L}^{-1}$ borate buffer ( $\mathrm{pH}$ 9.2), the separation of $\mathrm{I}^{-}$and $\mathrm{IO}_{3}{ }^{-}$took $25 \mathrm{~s}$ with LODs of 0.12 and $0.13 \mathrm{fg}$, respectively.

Takasaki et al. ${ }^{54}$ have developed a highly efficient sample introduction system comprising an inert loop injector, HPCN and a temperature-controlled cyclone spray chamber at $60{ }^{\circ} \mathrm{C}$ coupled with ICP-MS. An injection volume of $20 \mu \mathrm{L}$ into a carrier at a flow rate of $10 \mu \mathrm{L} \mathrm{min}^{-1}$ was possible, resulting in a stable signal for $100 \mathrm{~s}$. The authors claim that the system gives similar sensitivity to a conventional nebulizer operating at $1 \mathrm{~mL} \mathrm{~min}^{-1}$ and have used it to interface HPLC with ICP-MS for the determination of DNA fragments. ${ }^{55}$

\subsubsection{Thermal vaporization}

Tungsten coil ETV has been used successfully as a sample introduction method in atomic spectroscopy for some time. The benefits of the approach include its mass production, ease of use and low power requirement. A review by Hanna and Jones ${ }^{56}$ focused on the use of the 
tungsten coil as an ETV sample introduction source in atomic absorption, emission, and fluorescence spectrometry over the past decade. Analyzed samples had both biological and industrial significance, illustrating the versatility of the technique. Hanna et al. ${ }^{57}$ continue to demonstrate innovative uses of the tungsten coil for ETV, by constructing a portable flame AES device combining the ETV with a welding industry cutting torch as the flame source. The emission signal from the air-acetylene flame was focussed onto a miniature CCD spectrometer. Figures of merit were determined for five alkaline and alkali earth metals of biological and environmental significance. Limits of detection were, on average, 100 times lower than those for traditional flame emission spectrometers. The capabilities of this portable device make it an ideal tool for biological field analysis, particularly in areas where traditional laboratories are inaccessible.

A compact, aluminium ETV cell was constructed for ICP-OES by Hanna et al. ${ }^{58}$. The cell occupied the space normally filled by the spray chamber and fitted directly to the quartz torch using a simple compression fitting without any tubing. The compact ETV allowed sample volumes as low as $10 \mu \mathrm{L}$ to be analyzed with an automated control program for efficient vaporization. Twelve elements were analyzed utilizing a time resolved acquisition method so that real-time data could be generated over a period of $10 \mathrm{~s}$ with an improvement in detection limits of an average factor of 14 for elements over a wavelength range of 193-445 nm.

Foltynova and co-workers ${ }^{59}$ developed a sample introduction method for ICPMS that used a NIR diode laser for thermal vaporization. The NIR diode laser is significantly less expensive than high-energy pulsed lasers traditionally used for LA. The lower power of the NIR diode laser is still sufficient to produce a sample aerosol allowing quantitative determination of metals in sub $\mu \mathrm{L}$ volumes of liquid samples. The limits of detection for $\mathrm{Co}, \mathrm{Ni}, \mathrm{Zn}, \mathrm{Mo}, \mathrm{Cd}$, $\mathrm{Sn}$, and $\mathrm{Pb}$ were found to be in the range of 0.4-30 pg. The method was characterized, optimized, and applied to the determination of $\mathrm{Co}$ in a drug preparation, $\mathrm{Pb}$ in whole blood, and $\mathrm{Sn}$ in food samples without any sample pretreatment. Beauchemin et al. ${ }^{60,61}$ described the use of a pre-evaporation tube (PET) heated to $400{ }^{\circ} \mathrm{C}$, inserted between a multi-mode sample introduction system (MSIS) and the plasma torch for sample introduction to an ICPAES. This modification improved the simultaneous determination of hydride forming and other elements compared with conventional sample introduction. Using an ultrasonic nebulizer MSIS-PET arrangement, a 10 to 25-fold improvement in sensitivity and LOD were obtained for a range of elements including $\mathrm{As}, \mathrm{Bi}, \mathrm{Hg}, \mathrm{Sb}$ and $\mathrm{Sn}$. The improvement was 
more significant for ionic emission lines than atomic emission lines. In addition, plasma robustness was increased when the system was used. This was thought to be due to the hydrogen gas produced during hydride generation, which was reported to increase energy transfer within the plasma, and from the introduction of water vapour (with PET), which was reported to improve plasma stability as well as sensitivity.

An approach to the speciation of inorganic chromium using low-temperature ETV-ICP-MS was proposed by Chen and $\mathrm{Lu}^{62}$. In the method, diethyldithiocarbamate (DDTC) was used as both an extractant and a chemical modifier. Using optimized conditions, the detection limit of $\mathrm{Cr}^{\mathrm{VI}}$ was $0.045 \mu \mathrm{g} \mathrm{L}^{-1}$ and the RSD for $1.0 \mu \mathrm{g} \mathrm{L}^{-1} \mathrm{Cr}^{\mathrm{VI}}$ was $4.6 \%(\mathrm{n}=9, \mathrm{v}=10 \mu \mathrm{L})$. The linear range of the calibration curve was three orders of magnitude. The proposed method was applied to the determination of $\mathrm{Cr}^{\mathrm{III}}$ and $\mathrm{Cr}^{\mathrm{VI}}$ in water samples with recoveries of 94.3$103 \%$.

Pd has long been used as a "universal" modifier in analyses involving ETV as a sample introduction or atomization device. Traditionally, solutions of Pd have been used but results of recent studies suggest that Pd nanoparticles result in better ion signals when used in ETVICP-MS. Yi et al. ${ }^{63}$ prepared and characterized Pd nanoparticles for use as modifier in the determination of $\mathrm{As}, \mathrm{Cd}, \mathrm{Hg}, \mathrm{Pb}, \mathrm{Sb}$ and $\mathrm{Zn}$ in biological samples by ultrasonic slurry sampling ETV-ICP-MS. Analysis of SRMs provided results in good agreement with the certified values and the analyses of biological samples were also found to be in good agreement with the pneumatic nebulization ICP-MS results of the same solutions. The method detection limits estimated from standard addition curves were found to be in the range 1.9-3.6, 0.2-0.4, 0.5-0.8, 0.1-0.2, 0.4-0.8 and 0.4-0.6 $\mathrm{ng} \mathrm{g}^{-1}$ for $\mathrm{Zn}, \mathrm{As}, \mathrm{Cd}, \mathrm{Sb}, \mathrm{Hg}$ and $\mathrm{Pb}$, respectively, in samples.

\subsection{Vapour generation}

Long et al. have published a two-part review of advances in HG for analytical atomic spectrometry. The first part ${ }^{64}$ focuses on technique development (182 references) and part two $^{65}$ on the analysis of real samples (119 references). Matusiewicz and Sturgeon have reviewed chemical vapour generation with slurry sampling and its application to atomic and mass spectrometry ${ }^{66}$ in a review with 72 references.

\subsubsection{Chemical Vapour Generation}


Chemical vapour generation includes a range of methods used for generating a volatile form of an element so it can be introduced directly into an instrument for detection. This includes hydride generation $(\mathrm{HG})$ of elements such as $\mathrm{As}, \mathrm{Bi}, \mathrm{Ge}, \mathrm{Pb}, \mathrm{Sb}, \mathrm{Se}, \mathrm{Sn}, \mathrm{Te}$; cold vapour generation $(\mathrm{CVG})$ of $\mathrm{Hg}$; and formation of volatile organo-metallic compounds. Methods for the generation of volatile forms of $\mathrm{As}, \mathrm{Bi}, \mathrm{Sb}, \mathrm{Se}$ and $\mathrm{Hg}$ are well developed and widely used for routine analysis, so novel developments usually focus on the development of integrated systems.

Matusiewicz and Slachcinski have developed a microfluidic chip-based electrophoresis HG system coupled with MIP-AES for the determination of As species. ${ }^{67}$ The procedure involved separation of $\mathrm{As}^{\mathrm{III}}$ and $\mathrm{As}^{\mathrm{V}}$ with the chip-based CE, HG of the effluent, and nebulization using a MiraMist CE nebulizer. LODs of $3.9 \mathrm{ng} \mathrm{mL}^{-1}$ and $5.4 \mathrm{ng} \mathrm{mL}^{-1}$ were obtained for $\mathrm{As}^{\mathrm{III}}$ and $\mathrm{As}^{\mathrm{V}}$ respectively. Katzer et al. ${ }^{68}$ have studied interference by molecular oxygen and gaseous water on As and Se in QF-AAS at the $193.7 \mathrm{~nm}$ and $196.0 \mathrm{~nm}$ lines respectively. They found that oxygen gave rise to a structured spectrum whereas water resulted in a pseudo-continuum, and both were influenced by operating conditions. The mechanism of the chemical interference of $\mathrm{Ni}$ on $\mathrm{HG}$ of As and $\mathrm{Sb}$ with $\mathrm{NaBH}_{4}$ has been studied by Henden et al. ${ }^{69}$. They found that the most serious interference was caused when $\mathrm{Ni} / \mathrm{NiB}$ nanoparticles of $<40 \mathrm{~nm}$ diameter were formed during reduction, which sorbed $\mathrm{As} \mathrm{s}^{\mathrm{III}}$, $\mathrm{As}^{\mathrm{V}}$ and $\mathrm{Sb}{ }^{\mathrm{III}}$ species thereby preventing them from being reduced to their volatile hydrides. Analysis of the particles using EDX, XPS and XRD revealed that they had amorphous structure which varied depending on whether pure nitrogen (resulting in $\mathrm{Ni}_{2} \mathrm{~B}$ ) or air (resulting in $\mathrm{Ni}_{3} \mathrm{~B}$ or a possibly mixture of $\mathrm{Ni}(0)$ and $\mathrm{Ni}_{2} \mathrm{~B}$ ) was used during the reduction step. Sorption studies revealed that $\mathrm{Ni}(0)$ and $\mathrm{Ni}(\mathrm{OH})_{2}$ do not adsorb the analyte or their hydrides significantly. Another mechanistic study was undertaken by Pagliano et al. ${ }^{70}$, who used $\mathrm{NaBH}_{4}$ and $\mathrm{NaBD}_{4}$ to generate arsine from As ${ }^{\mathrm{III}}$, with subsequent analysis by AAS and GC-MS. They studied the interference caused by $\mathrm{Au}^{\mathrm{III}}, \mathrm{Pd}^{\mathrm{II}}, \mathrm{Pt}^{\mathrm{II}}, \mathrm{Ni}^{\mathrm{II}}$ and $\mathrm{Cu}^{\mathrm{II}}$ by measuring the effect on the isotopic composition of the arsine and found that a large amount of hydrogen from the solvent was incorporated even at very low concentrations of these concomitant ions. They postulated that intermediate species formed at an early stage in the reaction between the metal ion and the TDB-As complex giving rise to a 'mechanistic interference' in addition to the already known yield interference.

Becker et al. ${ }^{71}$ have developed a method for the determination of As in gasoline by HG-ETAAS in conjunction with preconcentration in the graphite tube coated with $150 \mu \mathrm{g}$ of 
Ir as a permanent modifier. A two-level factorial optimisation was used to identify the main effects and interactions, with optimal conditions being $2.7 \mathrm{~mol} \mathrm{~L}^{-1} \mathrm{HCl}$ and $1.6 \% \mathrm{w} / \mathrm{V} \mathrm{NaBH}$ for $\mathrm{HG} ; 250{ }^{\circ} \mathrm{C}$ trapping temperature and 30 s collection time. The LOD was $6.4 \mathrm{ng} \mathrm{L} \mathrm{L}^{-1}$ using these conditions. An automated multi-syringe FIA-HG-AFS system has been developed by Chaparro et al. ${ }^{72}$ for the determination of DMA, inorganic As and total As in BCR627 tuna. The system includes a UV photo-oxidation step to break down DMA and is capable of processing 24-28 samples $\mathrm{h}^{-1}$ with LOD of 0.09 and $0.47 \mu \mathrm{g} \mathrm{L}^{-1}$ for DMA and inorganic As respectively.

Deng et al. ${ }^{73}$ have used nano- $\mathrm{TiO}_{2}$ to adsorb $\mathrm{Se}^{\mathrm{IV}}$ at $\mathrm{pH} 8$ for pre-concentration, then mixed the slurry with $3 \% \mathrm{~m} / \mathrm{V} \mathrm{KBH}_{4}$ and $1 \% \mathrm{~m} / \mathrm{V} \mathrm{KOH}$ in $25 \% \mathrm{HCl}$ to generate the hydride for detection using AFS. They observed no interference from Fe, Ni, Co (up to $1000 \mathrm{mg} \mathrm{L}^{-1}$ ), $\mathrm{Cu}\left(500 \mathrm{mg} \mathrm{L}^{-1}\right), \mathrm{Ag}, \mathrm{Au}\left(100 \mathrm{mg} \mathrm{L}^{-1}\right)$ on $5 \mu \mathrm{g} \mathrm{L}^{-1} \mathrm{Se}^{\mathrm{IV}}$ and obtained an LOD of $0.0006 \mu \mathrm{g} \mathrm{L}^{-}$ ${ }^{1}$ for a $40 \mathrm{~mL}$ sample.

Chemical vapour generation of transition metals is a topic that still attracts some attention. Zeng et al. ${ }^{74}$ have developed a method for $\mathrm{CVG}$ of $\mathrm{Co}, \mathrm{Fe}$ and $\mathrm{Ni}$ in environmental and biological materials using the IL $\mathrm{C}_{4}-\mathrm{mim}_{-} \mathrm{PF}_{6}$ and $\mathrm{APDC}$ to enhance the efficiency of $\mathrm{CVG}$ to $42 \%, 61 \%$ and $54 \%$ respectively. Reduction was performed using $\mathrm{KBH}_{4}$ with optimised concentrations of $0.02 \%$ or $0.01 \%(\mathrm{~m} / \mathrm{V})$ APDC and $0.1 \%$ or $0.2 \%(\mathrm{~m} / \mathrm{V}) \mathrm{C}_{4}-\mathrm{mim}_{-}-\mathrm{PF}_{6}$ to yield LODs of 18,14 and $11 \mathrm{ng} \mathrm{mL}^{-1}$ for $\mathrm{Fe}$, Co and Ni respectively using FAAS detection. Cerutti et al. ${ }^{75}$ have developed an on-line method for CVG of Sc by acidified $(10 \% \mathrm{v} / \mathrm{v} \mathrm{HCl})$ $\mathrm{NaBH}_{4}$ after preconcentration onto a minicolumn of activated carbon at $\mathrm{pH}$ 7. The volatile Sc compound was then swept into an ICP-AES spectrometer to give an enhancement factor of 240 and an LOD of $4 \mu \mathrm{g} \mathrm{L}{ }^{-1}$.

\subsubsection{Electrochemical Vapour Generation}

Generation of volatile hydrides by electrochemical means has come to the fore in recent years. Saenz et al. ${ }^{76}$ have evaluated working electrodes fabricated variously from pyrolytic graphite, glassy carbon, platinum and cadmium for the electrochemical vapour generation $(\mathrm{EVG})$ of volatile $\mathrm{Pb}$ species. They used the same cell and varied the conditions, focussing on the variation of cathode hydrogen overvoltage at constant current for the different cathode materials, and measured the absorbance signal for $\mathrm{Pb}$ in a univariate optimization approach. Best results were obtained using a cadmium cathode, argon carrier gas $\left(55 \mathrm{~mL} \mathrm{~min}^{-1}\right)$, current 
of $0.8 \mathrm{~A}$ and $0.05 \mathrm{~mol} \mathrm{~L}^{-1} \mathrm{HCl}$ as the catholyte, giving an LOD of $0.21 \mu \mathrm{g} \mathrm{L}{ }^{-1}$. Zhang et al. ${ }^{77}$ have used titanium foil as the cathode for EVG of $\mathrm{Cd}$ and detection with AFS. They optimised the operating conditions to achieve an LOD of $0.15 \mathrm{ng} \mathrm{mL}^{-1}$ and RSD of $3 \%$ for a $20 \mathrm{ng} \mathrm{mL}^{-1}$ solution, and were able to successfully determine Cd in rice and water CRMs. In comparison, Arbab-Zavar et al. ${ }^{78}$ used EVG with QF-AAS for detection of $\mathrm{Cd}$ and achieved an LOD of $0.51 \mathrm{ng} \mathrm{ml}^{-1}$, though the abstract did not give any details of the cathode material. The same authors have also published a report ${ }^{79}$ on the EVG of Zn using a lead-tin alloy cathode and platinum electrode, with QF-AAS detection, so this may well be the system used in the aforementioned paper. Optimisation yielded an LOD of $11 \mathrm{ng} \mathrm{mL}^{-1}$ for $\mathrm{Zn}$ and linear calibration up to $300 \mathrm{ng} \mathrm{mL}^{-1}$. Accuracy was verified by analysis of CRMs.

Yang et al. ${ }^{80}$ have developed a novel solid polymer electrode for EVG of As, comprising a Nafion membrane (for gas separation and $\mathrm{H}^{+}$exchange), a soft graphite felt cathode and a Ti/Ir mesh anode. Electrolysis of water produced $\mathrm{H}^{+}$at the anode which was transferred to the cathode chamber where it reacted with $\mathrm{As}^{\mathrm{III}}$ to generate arsine. It is noteworthy that pure water rather than an acid analyte was used. The LOD for As ${ }^{\mathrm{III}}$ was 0.12 $\mu \mathrm{g} \mathrm{L}{ }^{-1}$, with $2.9 \%$ RSD for $\mathrm{n}=10$ replicate measurements of a $5 \mu \mathrm{g} \mathrm{L}^{-1}$ standard. The method was used for the determination of As in GBW07605 Tea CRM and tobacco samples with recoveries of between 97 and 103\%. Sengupta and Dasgupta ${ }^{81}$ have used a system with some similarities for selective EVG of As species. They used a cylindrical anode surrounded by a Nafion membrane and then a concentric graphite cathode, to give a chamber of only $115 \mu \mathrm{L}$ volume. They were able to selectively generate arsine from $\mathrm{As}^{\mathrm{III}}$ at a current of $0.1 \mathrm{~A}$, and both $\mathrm{As}^{\mathrm{III}}$ and $\mathrm{As}^{\mathrm{V}}$ at $0.85 \mathrm{~A}$. The LODs were was $0.09,0.76 \mu \mathrm{g} \mathrm{L}^{-1}$ for total As and As ${ }^{\mathrm{III}}$ respectively using gas-phase chemiluminesence detection.

Masrournia and Shadmehri ${ }^{82}$ have investigated EVG of Sn using cathodes of lead, tin, lead-tin alloy and glassy carbon in conjunction with nitric, sulfuric and hydrochloric acid catholytes. In addition, they used in situ trapping ETAAS with Ir, Pd, Pt and W modifiers. An

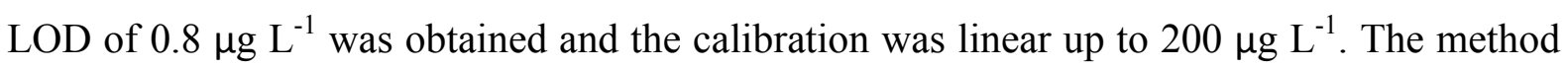
was applied to the determination of $\mathrm{Sn}$ in environmental waters, with spiked recoveries of between 93 and 115\%.

\subsubsection{Photochemical Vapour Generation}

Photochemical vapour generation (PVG) in the presence of organic acids has been the topic of some interesting research. Sturgeon and Grinberg ${ }^{83}$ have speculated that volatile species, 
formed by $\mathrm{Hg}, \mathrm{I}, \mathrm{Fe}, \mathrm{Ni}$ and Se in acetic and formic acid under the influence of UV light, are generated as a result of the photochemical generation of free radicals and ligand to metal charge transfer reductions and oxidations.

The greatest number of publications is on PVG of $\mathrm{Hg}$. Hou et al ${ }^{84}$ have used a miniaturised UV-LED in the presence of formic acid to generate $\mathrm{Hg}(0)$ from $\mathrm{Hg}^{\mathrm{II}}$ and detection using AFS. They reported an LOD of $0.01 \mu \mathrm{g} \mathrm{L}^{-1}$ and 3.2\% RSD under optimum conditions, with no interference from common ions and successful determination of $\mathrm{Hg}$ in DORM-3 fish muscle tissue CRM. Da Silva et al. ${ }^{85}$ have reported on the determination of total $\mathrm{Hg}$ (in ethanol biofuel samples, achieving an LOD of 0.05 to $0.09 \mu \mathrm{g} \mathrm{L}^{-1}$ and recovery of between 91-107\% under optimised conditions.

Matusiewicz et al. ${ }^{86}$ used Ag nano-particles immobilised on $\mathrm{TiO}_{2}$ to act as a catalyst for $\mathrm{PVG}$ of $\mathrm{Hg}$ in the presence of formic acid, and found that it offered improved performance compared with undoped $\mathrm{TiO}_{2}$ and $\mathrm{ZnO}$. They achieved from 95 to $99 \%$ recoveries from CRMs containing between 0.20-1.99 $\mu \mathrm{g}$ g-1 Hg, with RSDs of less than $11 \%$. Li et al. ${ }^{87}$ have also used a $\mathrm{Ag}-\mathrm{TiO}_{2}$-formic acid catalytic system for PVG of Se species, including the difficult to reduce $\mathrm{Se}^{\mathrm{VI}}$. LODs for $\mathrm{Se}^{\mathrm{IV}}, \mathrm{Se}^{\mathrm{VI}}$, selenocystine and selenomethionine were 1.2, 1.8, 7.4 and $0.9 \mathrm{ng} \mathrm{mL}^{-1}$ respectively, and $0.7,1.0,4.2$, and $0.5 \mathrm{ng} \mathrm{mL}^{-1}$ respectively for the $\mathrm{Ag}-\mathrm{ZrO}_{2}$-formic acid catalytic system when using FIA-AFS as the method of detection. These LODs were improved to c.a. $10 \mathrm{pg} \mathrm{mL}^{-1}$ for both systems when using ICP-MS detection and the methods were used for the determination of total Se in enriched yeast.

Nobrega et al. ${ }^{88}$ have used PVG for generation of volatile Cd species from an acetic acid medium using a thin film generator comprising a $20 \mathrm{~W}$ low pressure UV source. It was necessary to sweep the generated species with an argon gas stream containing $10 \%$ hydrogen into a QF atomiser heated to $900{ }^{\circ} \mathrm{C}$. The authors reported highly efficient PVG of $90 \%$ but problems with analyte transfer to the detector resulted in poor precision of $30 \% \mathrm{RSD}$.

A novel method of vapour generation, which may also be photochemical in nature, has been reported by Liu et al. ${ }^{89}$, who used a dielectric barrier discharge (DBD) to directly vaporize and atomize $\mathrm{Hg}$ from solution, with AFS detection. The DBD was generated between two concentric quartz tubes (outer: $5 \mathrm{~mm}$ i.d. and $6 \mathrm{~mm}$ o.d., inner $2 \mathrm{~mm}$ i.d. and $3 \mathrm{~mm} \mathrm{0.d}$.), the inner of which contained an embedded copper electrode. Sample solution was introduced to the outer surface of the inner tube and a plasma was generated in a suitable gas by application 
of a voltage. The LODs were $0.02 \mathrm{ng} \mathrm{mL}^{-1}$ for $\mathrm{Hg}^{\mathrm{II}}$, MeHg and $\mathrm{EtHg}$, and RSDs of between $4.3-6.2 \%(n=11)$ in the presence of formic acid. Accuracy was verified by determination of $\mathrm{Hg}$ in ZK020-2 freeze dried urine, GBW(E)080392 simulated water and GBW10029 tuna.

\subsection{Solids}

Methods of solids analysis are either direct, where vaporization, atomisation and excitation of the sample occurs together, such as arc/spark ablation, glow discharge analysis and secondary ion mass spectromery; or indirect, where vaporization is separate to atomisation and/or excitation, such as laser ablation or thermal vaporization coupled with a separate atomisation/excitation source. Many of the new developments in this area involve lasers or are related to isotopic measurements so are covered separately in sections 3 and 4 .

\subsubsection{Direct methods.}

1.3.1.1 Arc \& spark. DC arc methods have been used for the direct analysis of metal samples since the early days of instrumental techniques. Research publications dating back to the 1930's report the use of a DC arc for direct copper analysis. A modification of the most commonly used DC arc technique, described as the "globule arc method" was described in 1959 for the determination of copper. The approach involves melting the copper sample to a globule by action of the arc and either fully or partially melting to evaporate the copper. Inspired by this globular method, Hassler et al. ${ }^{90}$ developed an ETV-ICP AES method for the determination of 22 elements in high-purity copper. A range of halogenated gases were evaluated as modifiers, with $\mathrm{CHF}_{3}$ being found to be the most effective for achieving in-situ analyte matrix separation. Limits of quantification ranging from $0.6 \mathrm{ng} \mathrm{g}^{-1}$ to $29 \mathrm{ng} \mathrm{g-}^{1}$ were achieved.

1.3.1.2 Secondary ion mass spectrometry. SIMS is a surface sensitive analysis technique with low detection limits. The main drawback, however, is the high occurrence of ionizationand sputter-induced matrix effects which results in difficulty obtaining valid quantitative information. Coating the surface of an organic sample with a very thin layer of noble metal (metal-assisted SIMS) prior to static SIMS increases the characteristic secondary ion intensities. Becker and Wirtz ${ }^{91}$ performed this metal-assisted SIMS approach for the analysis of polymer blend samples and found that the matrix effects were also reduced. The results were attributed to diffusion processes leading to a sample surface configuration consisting of individual polymer chains embedded in a common Ag matrix. 


\section{Instrumentation, Fundamentals and Chemometrics}

\subsection{Instrumentation}

This section covers the development of new instrumentation, such as the development of completely new techniques, novel developments in atom cells, excitation sources, monochromators, mass spectrometers and detectors.

This year there seems to have been a resurgence in the development of sources for atomic spectrometry. In the past this has manly focussed on the miniaturization of existing sources, however, there now seems to be some development of new miniature sources based on novel methods of plasma discharge. Kohara et al. ${ }^{92}$ described a liquid electrode plasma (LEP) source for AES. The source works by generating a vapour bubble inside a restriction in a microchannel by using a high voltage DC pulse of $2.5 \mathrm{kV}$ and less than $3 \mathrm{~ms}$, which generates a plasma in the bubble with $\mathrm{T}_{\mathrm{exc}}=8000 \mathrm{~K}$ and $\mathrm{n}_{\mathrm{e}}=10^{15} \mathrm{~cm}^{-3}$. A two-step emission process was observed to occur corresponding to a first expansion and contraction of the bubble at atmospheric pressure, followed by a second during re-expansion under reduced pressure to yield higher atomic emission and lower background. The LOD was $4.0 \mu \mathrm{g} \mathrm{L}^{-1}$ for $\mathrm{Pb}^{92}$. The technique has been applied to the measurement of human chorionic gonadotrphin protein (hCG) tagged with a Ag nanoparticle-antibody complex, whereby it was necessary to first dissolve the nanoparticles in nitric acid prior to LEP-AES detection, with an LOD of 1.3 pg $\mathrm{mL}^{-1}$ for hCG.

A dielectric barrier discharge (DBD) has also been used by Fan et al. ${ }^{93}$ to generate a plasma inside a $200 \mathrm{~nL}$ microbubble in silicone oil generated in the gap between parallel plates, using different dissolved gases, Ar, He and Ar-He mixtures. They observed atomic emission spectra for air, Ar and He. A report by He et al. ${ }^{94}$ described a DBD generated in a similar way, using copper and and tungsten wire electrodes separated with a glass slide to act both as the dielectric barrier and sample plate. Samples $(<80 \mu \mathrm{L})$ in $1 \mathrm{~mol} \mathrm{~L}^{-1} \mathrm{HNO}_{3}$ were deposited on the plate and the plasma ignited between the tungsten wire and liquid surface using a $3.7 \mathrm{kV}$ voltage at $30 \mathrm{kHz}$, to yield atomic emission of $\mathrm{Cd}, \mathrm{Cu}, \mathrm{K}, \mathrm{Na}, \mathrm{Zn}$, and with LODs between 7-79 $\mu \mathrm{g} \mathrm{L}^{-1}$. The authors cite the discreet sampling capability, low cost and simplicity as an advantage for field analysis, but do not describe the optical detection system in the abstract which presumably would be the limiting factor. 
Capacitively coupled plasmas (CCPs) have attracted much attention in recent years. Two papers by the same group ${ }^{95,96}$ described the characterisation and application of a CCP constructed with a molybdenum tubular electrode and either one or two ring electrodes, operated with a flow of $0.4 \mathrm{~L} \mathrm{~min}^{-1}$ argon and at $275 \mathrm{~W}$ power. Under these conditions the degree of ionization was calculated to be between $73-85 \%$ for $\mathrm{Ca}, \mathrm{Cd}, \mathrm{Mg}$ and $\mathrm{Mn}$ with tworing electrodes. The source was used for multielement determinations in multimineral/multivitamin preparations after microwave digestion which yielded LODs in the range $0.003(\mathrm{Na})$ to $1.5(\mathrm{P}) \mathrm{mg} \mathrm{g}^{-1}$, and recoveries of between $90-107 \%$ for QC samples.

A digitally controlled rotating field plasma source has been investigated by Jankowski et al. ${ }^{97}$. The non-stationary, helium plasma is sustained by a rotating electric field between five electrodes in a plane around the axis, with the plasma temporarily stretched between at least two electrodes. Operating conditions are adjustable for frequency (6-100 $\mathrm{Hz})$, power $(50-250 \mathrm{~W})$ and plasma gas flow $\left(100-1500 \mathrm{~mL} \mathrm{~min}^{-1}\right)$ to give $\mathrm{T}_{\mathrm{exc}}=2200-3300$ $\mathrm{K}, \mathrm{T}_{\text {rot }}=1600 \mathrm{~K}$ and $\mathrm{n}_{\mathrm{e}}=0.6-2.0 \times 10^{14} \mathrm{~cm}^{-3}$. The source was used for the determination of hydride-forming elements and $\mathrm{Hg}$ at the $\mathrm{ng} \mathrm{mL}^{-1}$ level.

A microwave ion source has been adapted for $A M S^{98}$. The source was operated at $2.45 \mathrm{GHz}$, was coupled with a magnesium charge exchange channel, and samples of $\mathrm{CO}_{2}$ were injected through a glass capillary at a flow rate of $370 \mu \mathrm{L} \mathrm{min}^{-1}$ resulting in $400{ }^{14} \mathrm{C}_{\text {counts s}}{ }^{-1}$ for a 'modern' sample ( $\sim 0.2 \%$ efficiency). The source has been used successfully for routine measurements but calculations by the authors suggest that they can improve the ion transport efficiency. A new type of primary ion source for SIMS has been presented by Xu et al. ${ }^{99}$, in which ions were produced at atmospheric pressure before being extracted into vacuum. A tuneable fragmentation ion source, formed from a DC-pulsed GD, has been further investigated by Lotito and Gunther ${ }^{100}$, coupled with LA and TOF-MS for characterisation of oleic acid, reserpine and peptides. Both 'hard' and 'soft' ionization regimes were studied and compared with MALDI and found to yield similar spectra but lower sensitivity. An MIP initiated by laser- or spark- induced breakdown, and sustained in air, has been developed by Ikeda and Tsuruoka ${ }^{101}$ for analysis of molecular gases such as $\mathrm{O}_{2}$ or $\mathrm{N}_{2}$. They observed an improvement in the peak intensity of $\mathrm{Pb}$ spectra obtained by LIBS and SIBS (spark induced breakdown spectroscopy) of 15 -fold and 850-fold respectively when used in conjunction with the MIP, without an increase in background noise. 
Labusov et al. ${ }^{102}$ presented an overview of the current status of multichannel analysers used in AES, specifically multicrystal assemblies of photodiode arrays. Hadjar et al. ${ }^{103}$ have reported some performance data for an IonCCD detector developed for a Mattauch-Herzog miniature MS. They state that the two major energy loss processes at $\mathrm{keV}$ ion kinetic energies are nuclear stopping and secondary electron emission. The former was found not to result in damage to the detector under typical operating conditions; and the latter could be suppressed by retarding the ions, or increasing the B-field of the ionCCD, to allow quantitative MS.

Collon et al. ${ }^{104}$ reported the first use of ${ }^{39} \mathrm{Ar}$ AMS and the gas-filled magnet technique to separate ${ }^{39} \mathrm{~K}$ and ${ }^{39} \mathrm{Ar}$ isobars. They used a quartz liner in the plasma chamber and ICR ion source to reduce ${ }^{39} \mathrm{~K}$ by a factor of 130 , resulting in a detection sensitivity of $4 \times 10^{-17}$ for the ${ }^{39} \mathrm{Ar} /$ Ar ratio.

Lee et al. ${ }^{105}$ developed an AES instrument for the detection of the absolute spectral radiant excitance of UV signatures in the range $240-440 \mathrm{~nm}$, using a heated graphite black body furnace at $3000 \mathrm{~K}$. They evaluated the instrument by measuring molecular emission in a butane flame, with a claimed uncertainty of $1.66 \%$ for the absolute UV emission signature.

\section{$2.2 \quad$ Fundamentals}

Coverage is confined to a consideration of fundamental studies related to instrumental methods used primarily for analytical atomic spectrometry, and excludes studies related to e.g. astronomy and sputtering sources, except where particularly relevant.

The search for naturally occurring superheavy elements continues. Marinov et al. ${ }^{106}$ comment on the fact that their results have not been confirmed by other workers by stating that this could be due to the nature of the experiment, namely that analysis of unrefined ores is less likely to yield a positive result compared to analysis of homogeneous materials extracted from large quantities of ore. They also point out that counts at masses 296 and 294 seen by other workers could be due to ${ }^{296} \mathrm{Rg}$ and ${ }^{294}$ eka-Bi in long-lived isomeric states, which would support their findings. Separately, Ludwig et al ${ }^{107}$ have used AMS to scan pure platinum at thirteen masses in the range $292-310 \mathrm{~m} / \mathrm{z}$, and $292 \mathrm{~m} / \mathrm{z}$ and $298 \mathrm{~m} / \mathrm{z}$ in pure osmium and pure lead fluoride respectively, but could not attribute any events to superheavy elements. 
Civis et al. ${ }^{108}$ have determined the transitions and oscillator strengths for $\mathrm{Na}(\mathrm{I})$ spectra in the 1.4-14 $\mu \mathrm{m}$ range. They used laser ablation $(1.0 \mathrm{kHz}, \mathrm{ArF}, 193 \mathrm{~nm}, 15 \mathrm{~mJ})$ of NaI inside a vacuum chamber $\left(10^{-2}\right.$ Torr) to generate excited $\mathrm{Na}(\mathrm{I})$ vapour, and FT-IR to record the spectrum. They report measurements for $26 \mathrm{Na}$ I lines, including 20 lines not measured before, energy transitions for the newly observed $7 \mathrm{~h}, 6 \mathrm{~h}$ and $6 \mathrm{~g}$ levels and improved determinations for the already known levels $4 \mathrm{~s}, 4 \mathrm{p}, 5 \mathrm{p}, 6 \mathrm{p}, 5 \mathrm{f}$ and $5 \mathrm{~g}$.

A long standing favourite is the spectroscopic measurement of the temperatures which characterise a particular plasma discharge, typically $\mathrm{T}_{\text {rot }}, \mathrm{T}_{\mathrm{exc}}, \mathrm{T}_{\mathrm{ion}}$ and $\mathrm{n}_{\mathrm{e}}$. Novosad et al. ${ }^{109}$ have investigated a $13.56 \mathrm{MHz}$ plasma jet discharge operated at argon flow rates of between 0.3 (carrier) and 4.0 (plasma) $\mathrm{L} \mathrm{min}^{-1}$, and $140 \mathrm{~W}$ power. They calculated characteristic temperatures from $\mathrm{OH}$ band spectra, $\mathrm{Ar}$ and $\mathrm{H}_{\beta}$ lines for $\mathrm{T}_{\text {rot }}=800 \mathrm{~K}$ and $\mathrm{T}_{\text {exc }}>4000 \mathrm{~K}$; and LODs of $27(\mathrm{Ca}), 49(\mathrm{Cu}), 58(\mathrm{Mg}), 40(\mathrm{Li}), 13(\mathrm{Na})$ and $180(\mathrm{Zn}) \mu \mathrm{g} \mathrm{L}^{-1}$. A semiquantitative ICP-AES method has been developed by Dettman and Olesik ${ }^{110}$ by determining the temperature using the ion/atom ratio under the assumption of partial LTE. They found that the partial LTE temperatures were in better agreement for nine different ion/atom line pairs tested than when using an LTE model, and fell within the range $8100 \pm 300 \mathrm{~K}$. This allowed them to measure the sensitivity of a single emission line for an element using a single standard and obtain semi-quantitative concentrations within a factor of three for $85 \%$ of the 227 emission lines (66 elements) studied. Wiltsche et al. ${ }^{111}$ have measured the effect of foreign gases $\left(\mathrm{CO}_{2}, \mathrm{H}_{2}, \mathrm{He}, \mathrm{N}_{2}\right)$ on the rf frequency of a free-running, argon ICP by including a small probe coil in the plasma torch. Their main finding was that the plasma extinguished at a constant, characteristic frequency when the flow of foreign gas introduced to the central channel became too high, and proposed this as a method for predicting the maximum tolerable foreign gas flow. MacIntyre et al. ${ }^{112}$ have continued the work on the determination of dissociation temperature for $\mathrm{ArO}^{+}$in ICP-MS. In this latest paper they addressed the inconsistencies observed in the determination of $\mathrm{T}_{\text {gas }}$ by comparing experimental and theoretical ion ratios for the dissociation of $\mathrm{ArO}^{+}$, and attributed this to the inclusion of the low-lying, excited ${ }^{2} \Pi$ electronic state in the partition function. They further noted that $\mathrm{ArO}^{+}$ in the ${ }^{2} \Pi$ state dissociated into $\mathrm{Ar}^{+}$and $\mathrm{O}$, whereas in the ${ }^{4} \Sigma$ state it dissociated into $\mathrm{Ar}$ and $\mathrm{O}^{+}$, and that if adjustments were made in the calculation to take account of this then reasonable $\mathrm{T}_{\text {gas }}$ values of 2100-3500 K resulted. 
Matrix effects have been the subject of much research over the years and, despite being touted as 'relatively free' of such effects, ICP-MS is no exception to this. A review of 232 references on the subject has been published by Agatemor and Beauchemin ${ }^{113}$ focussing on representative references to describe the main issues rather than an exhaustive review.

The properties of the ICP-MS interface has also attracted the interest of several workers. Aghaei et al. ${ }^{114}$ have studied the effects of the MS interface on ICP characteristics in ICP-MS using a computational model, which predicted a dramatic increase in the plasma velocity close to the interface. Significantly, the model also predicted that the plasma termperature and electron density were lowered in the axial channel close to the sampling cone, but increased off-axis, so the position of the sampling cone was critical to achieve consistent results. Flamigni et al. ${ }^{115}$ have used particle image velocimetry to determine the velocities of particles passing through the load coil of an ICP. Particles were generated using LA of solid targets or drying microdroplets from a piezoelectric quartz capillary, and found to have velocities of between 10-20 $\mathrm{ms}^{-1}$ depending on axial position and operating conditions such as power, gas flow rate, injector diameter and the addition of $\mathrm{He}$ as a foreign gas. Interestingly, they observed particle acceleration over the axis of the load coil of 300-1000 $\mathrm{ms}^{-2}$. Murzatin et al. ${ }^{116}$ have also used microdroplets and NPs as probes for the investigation of spatial effects in the ICP by studying the atomisation process end-on and side-on. They observed significant spatial shifts in the position of atomisation, depending on operating conditions, particle size and the presence of concomitant elements, which have consequences for, e.g. sampling depth in ICP-MS.

Amais et al. ${ }^{117}$ have taken an alternative approach to interference correction in ICP-MS, whereby they used ions such ${ }^{36} \mathrm{Ar}^{+},{ }^{36} \mathrm{ArH}^{+}$and ${ }^{38} \mathrm{Ar}^{+}$, deriving from the plasma gas to correct for interferences at $\mathrm{m} / \mathrm{z} 32,34,55$ and 56 caused by other polyatomic ions. They successfully determined S, Mn and Fe in a variety of CRMs, meat and grain samples, with recoveries of between $72-105 \%$ for analyte concentrations between 4.42 to $7270 \mu \mathrm{g} \mathrm{g}^{-1}$. They extended this approach to the determination of $\mathrm{P}$ and $\mathrm{S}$ in fuel samples ${ }^{118}$, with LODs of 5 and $600 \mu \mathrm{g} \mathrm{L}^{-1}$ respectively.

Si has long been a problematic analyte in ET-AAS due to the formation of stable $\mathrm{SiC}$ and a number of modifiers have been suggested to improve the analysis. Heinirich and Kipphardt ${ }^{119}$ have used methane as a modifier by applying a methane/argon mixture during 
the pyrolysis step. This modification resulted in improvements in thermal stabilization, signal enhancement and shape of absorbance signals. These effects were attributed to the thermal decomposition products of methane, namely hydrogen and carbon black (soot). Characteristic masses of 50 and $30 \mathrm{pg}$ were obtained for standard transversely heated graphite atomizer (THGA) tubes and end-capped THGA tubes, respectively, which were lower than with other previously applied modifiers. A limit of detection of $0.2 \mu \mathrm{g} \mathrm{L}^{-1}(3 \sigma, \mathrm{n}=10)$ has been obtained. In addition, the gaseous modifier did not contribute to contamination which can be significant when a liquid modifier is co-injected with the sample. The proposed method was applied successfully to the determination of silicon in ultrapure water, nitric and hydrochloric acids.

Mini graphite tubes with internal diameters of $1 \mathrm{~mm}, 1.5 \mathrm{~mm}$ and $2 \mathrm{~mm}$ have been developed and adapted for use in high-resolution continuum source ET-AAS ${ }^{120}$. Use of a 2 $\mathrm{mm}$ tube resulted in no loss of lamp radiation when compared to the use of a $5.8 \mathrm{~mm}$ standard tube, while the use of $1.5 \mathrm{~mm}$ and $1 \mathrm{~mm}$ tubes resulted in about $20 \%$ and $70 \%$ loss of lamp radiation, respectively. Liquid samples of $1-5 \mu \mathrm{L}$ were introduced to the tube through an end hole using a conventional autosampler. Due to the smaller atomizer volume, analytical sensitivity was improved. For 51 of the 62 elements tested, improvements in sensitivity using a $2 \mathrm{~mm}$ tube over a $5.8 \mathrm{~mm}$ tube of factors of 6 to 12 were obtained. The feasibility of the mini tube concept for sample analysis was demonstrated by the determination of elements in model and real sample solutions with inorganic and organic matrices, yielding reliable results in all cases. The mini tubes provided high absolute sensitivity and could be used for ultratrace analysis of small samples. An ETV in the form of a "crucible with separated zones" has been designed and used by Oreshkin and Tsizin. ${ }^{121}$ This design allows separation of vaporization and atomization processes in a similar manner to the cup-in-tube or filter furnace designs and exposes the analyte to an isothermal analytical zone. Analytical figures of merit for the determination of $\mathrm{Ag}, \mathrm{Cd}$, and $\mathrm{Pb}$ in suspensions of organic and mineral components, concentrates, natural waters, and bottom sediments were found to be improved when compared to conventional tube furnaces.

\subsection{Chemometrics}

For the purposes of this review chemometrics relates to a range of mathematical techniques and algorithms used for the interpretation of analytical data, correction of interferences, and instrument calibration. 
The quality of the initial instrument calibration is critical in analytical atomic spectrometry. De Beer et al. ${ }^{122}$ have presented new mathematical models which demonstrate the extent to which the number of calibration points defines the value of the quality coefficient for different values of ' $\mathrm{g}$ ' (a parameter which controls the symmetry of the prediction interval of the abscissa value obtained from the confidence intervals around the curve). The result of this appeared to be that it was much harder to predict the quality of the calibration than is generally thought, and the authors provided an elaborated example of how to improve the quality of the calibration by lowering the g-value beneath a critical value.

Prikler and Einax have published two papers on the use of the wavelet transform in atomic spectrometry. ${ }^{123,124}$ In the first, they used Symlet4 to improve the LOD for As speciation using HPLC-ICP-MS and Cd determined by HR-CS-AAS, claiming up to 7-fold improvement for spectral peaks which have a Gaussian distribution. In the second, they compare the wavelet transform with Gaussian distribution and Fourier transform to reduce noise for As speciation using HPLC-ICP-MS, with wavelet transform yielding the greatest (6-fold) improvement. Reisenberg et al. ${ }^{125}$ have used PCR to reduce flicker noise in ICP-AES for the determination of $\mathrm{Bi}, \mathrm{Te}$ and $\mathrm{Sb}$ in thermoelectric films. By measuring multiple lines and pooling the regression the LOQs were lowered and precision improved. Wang et al. ${ }^{125}$ have used PLS to correct for matrix interferences in ICP-AES, caused by up to a 20,000:1 matrix:analyte ratio, with recoveries of $105 \%$. They also found that penalized PLS improved the accuracy further when the interference had a non-linear correlation with the matrix component.

\section{$3 \quad$ Laser-based Atomic Spectrometry}

The latest developments and studies related to laser-based atomic spectrometry are reviewed. This section is divided into two parts, following the same format as in previous ASU reviews. The first part is related to atomic spectrometry techniques where the laser is used as an intense energy source (e.g. LIBS); the second part deals with techniques where lasers are used as a bright radiation source of precise wavelength (e.g. laser excited atomic fluorescence or laser atomic absorption). The use of lasers for fundamental studies of the properties of atoms, and applications to studies involving thin film deposition will not be covered. Also not covered will be papers where lasers are used to vaporize a solid sample (laser ablation or LA) for detection with an ICP based instrument such as LA-ICP-MS or LA-ICP-AES.

\subsection{Lasers as energy sources}


Laser energy sources can be used to induce a plasma on a sample in order to generate a population of representative excited or ionized species. Different parameters will affect this process, including the laser energy, wavelength (typically from the ultraviolet to the infrared spectral region) or the pulse duration (typically from the nanosecond to the femtosecond time scale). Laser induced breakdown spectroscopy (LIBS) is highlighted as one of the most important techniques where a laser is used as an energy source to induce an optical plasma. This review describes the latest instrumental developments and fundamental studies related to LIBS, but it does not cover in detail LIBS applications.

\subsubsection{Laser induced breakdown spectroscopy (LIBS)}

In LIBS, a high-power pulsed, focused laser beam interacts with the surface of a sample (e.g. solid, liquid or aerosol sample) causing the removal of mass (ablation). During this process, other complex and not yet fully understood processes take place within the sample, including rapid local heating, melting, and vaporization. The ablated material compresses the surrounding atmosphere and leads to the formation of a shockwave. This evaporated mass shockwave produces a plume above the sample surface, then high temperature is achieved leading to the formation of a plasma which contains neutral and excited (atomic and ionic) species of the ablated mass, whose light emission constitutes the analytical signal. Hahn et al. ${ }^{126}$ have discussed the fundamental and diagnostics aspects of LIBS in an updated review, including instrumental and analytical approaches (e.g., double- and multi-pulse LIBS), calibration-free approaches, hyphenated approaches (e.g. Raman and fluorescence coupled with LIBS), resonantly enhanced LIBS, and signal processing (e.g., signal-to-noise analysis). Pathak et al. ${ }^{127}$ have published a review focused on the assessment of LIBS for the analysis of biomaterials, food materials, medicinal plants and industrial waste.

LIBS also has been established as a versatile and academic analytical technique, which can be used in the laboratory to introduce undergraduate students to atomic spectroscopy. In particular, students can gain valuable experience with atomic spectra, spectral interferences, calibration curves, detection limits. ${ }^{128}$

3.1.1.1 Fundamental Studies. The latest fundamental are briefly described by Moon et al. ${ }^{129}$ who further investigated the departure of local thermodynamic equilibrium (LTE) in a LIBS plasma at short delay times using two diagnostic approaches. The first approach is based on the temporal behavior of the ratio between selected atomic and ionic transitions, and the nearby spectral continuum (line-to-continuum approach); the measurements confirm that $\mathrm{T}_{\mathrm{exc}}$ 
and $\mathrm{T}_{\text {ion }}$ differ substantially at early delay times after the formation of the plasma. The second approach is based on the behavior of the ion fraction versus the ionization potential for different elements, showing that the agreement between experimental and theoretical LTE behavior improves as the delay time increases.

Additional studies related to the analytical performance of LIBS at different pressure conditions have been evaluated. For instance, Zimmer et al. ${ }^{130}$ investigated the feasibility of LIBS for measurements of equivalence ratio at high-pressures. In particular, LIBS was performed in a static cell containing mixtures of gases (e.g. $\mathrm{N}_{2}, \mathrm{C}_{2}$ ) at pressures up to $5 \mathrm{MPa}$. Additional LIBS experiments to achieve correlations between the values of emission intensity ratio of $\mathrm{H} / \mathrm{O}, \mathrm{H} / \mathrm{N}$ and the equivalence ratio of premixed kerosene/air mixture were performed by Zhang et al. ${ }^{131}$ at elevated pressure and temperature conditions which simulate a supersonic combustion state.

Automated interpretation of LIBS data has become a useful tool for analysis due to the great number of spectra that can be acquired in a relatively short time. For example, Banaee et al. ${ }^{132}$ employed a combination of LIBS with statistical methods to analyze and identify recyclable polymers. Discriminant function analysis (DFA) establishes a model based on the spectral line ratios of $\mathrm{C}, \mathrm{CN}, \mathrm{C}_{2}, \mathrm{~N}, \mathrm{Cl}, \mathrm{O}$ and $\mathrm{H}$, to successfully predict group members of the recyclable polymers. Similarly, multivariate analysis have been evaluated with standoff LIBS to determine the effectiveness of classifying thin explosive residue layers on painted surfaces, ${ }^{133}$ and to improve analytical determination of major elements in geological samples. ${ }^{134}$ In this latter work the multivariate regression technique of 'least absolute shrinkage and selection operator' (LASSO) provided accurate results using a reduced number of correlation coefficients. The LASSO technique is useful for understanding the underlying physical processes that give rise to LIBS emission, determining which lines can best represent each elemental concentration, and which lines from concomitant elements are causing matrix effects. Comparative studies of different data-driven multivariate statistical predictive algorithms, such PCR, PLS, MB-PLS, and S-PLS, have been performed by Yaroshchyk et al. $^{135}$ for the quantitative analysis of $\mathrm{Fe}$ in iron ore. The studies demonstrate that MB-PLS and S-PLS provide inferior performance in comparison with both PCR and PLS. Fuzzy logic approaches have been adapted to LIBS data interpretation by Hatch et al. ${ }^{136}$ in order to get a high degree of confidence in spectral assignment.

3.1.1.2 Instrumentation. LIBS is a useful technique for industrial applications because it can provide stand-off elemental analysis of materials in any aggregate state. For instance, the 
analysis of molten materials might allow real-time monitoring of melt composition in recycling furnaces or in metallurgical processes. Matiaske et al. ${ }^{137}$ have developed a mobile double-pulse stand-off LIBS system for industrial environments which can quantify metal oxides in mineral melts. Furthermore, the development of field-deployable LIBS instruments is of great interest for a wide variety of applications. For example, the application of chemometric analysis to the LIBS spectrum recorded by relatively low-resolution portable spectrometers has been shown to be appropriate for the identification of $U$ compounds and explosives $^{138}$, or for the determination of minor elements in steels using a microchip LIBS laser. ${ }^{139}$ Other field applications, such as the determination of elemental isotopes, might require the use of LIBS instruments combined with higher resolution spectrometers. Cremers et al. ${ }^{138}$ have evaluated a field-deployable hand-held LIBS interrogation probe combined with two high-resolution spectrometers, which are smaller and lighter in weight than those typically used for isotopic analysis, in order to demonstrate rapid in situ detection of isotopes of $\mathrm{U}, \mathrm{H}$ and Li.

For stand-off capabilities, NIR lines are more practical and easier to use with fibre optics than lines in the VUV, which need atmospheres of $\mathrm{N}_{2}$ or Ar, for example. For instance, recommended $\mathrm{S}$ emission lines are either in the VUV region $(125-180 \mathrm{~nm})$ or in the NIR region $(\sim 920 \mathrm{~nm})$, however, most detectors (e.g. CCD or ICCD cameras) have rapidly decreasing quantum efficiency in the NIR. Gagnon et al. ${ }^{140}$ developed a prototype spectrometer based on the use of a multiband volume phase grating coupled to a photodiode detector, for the determination of S using the NIR emission line. This spectrometer uses a denominated volume Bragg grating.

Zorba et $a l .{ }^{141}$ demonstrated the use of LIBS as a versatile, light element-sensitive technique for direct chemical analysis of interfacial layers. Nanometer-scale depth resolution has been achieved for elemental and molecular depth profiling of electrolyte interfaces used in electrochemical energy storage systems. LIBS depth profiling capability has also been verified for the quantitative analysis of multilayer structures simulating plasma facing components covered with deposited impurity layers. Almaviva et al. ${ }^{142}$ have designed and optimized a remote LIBS system working at vacuum conditions that could be used to monitor the composition of the plasma facing component surface layer of working fusion devices (e.g. ITER), providing information on the possible plasma pollution and fuel retention. Enhancement of ablation rate, which could be of great interest for the analysis of deep metallic layers, has been investigated by Cabalín et al. ${ }^{143}$ using double-pulse LIBS on metals 
covered by poly-dispersed water aerosol and water droplets. The mass removal efficiency was increased up to 20 times with respect to the LIBS process on dry surfaces.

Hyphenated approaches are used to increase the sensitivity and information gathered using LIBS. For example, the characteristics of microwave plasmas induced by lasers and sparks have been investigated by Ikeda et al. ${ }^{101}$. In general terms, after initial generation, a LIBS plasma is then grown and sustained by microwaves in air. The resulting MIP has a long lifetime, large volume, strong emission intensity, and high stability with time, making it suitable for applications in the molecular analysis of gases (e.g. $\mathrm{OH}$ or $\mathrm{N}_{2}$ ). It is important to highlight that the MIP is controlled by the input power and duration of the microwaves, and does not depend on the initial laser or spark plasma seeds. As a result, spectral intensity and signal to noise ratio could be further optimized, improving the analytical performance of LIBS. Additionally, an MIP enhanced light source could be used to make the total system smaller and cheaper than a conventional LIBS system, being very useful for real-time and in situ analysis of gas molecules (e.g. food processing, medical applications, chemical exposure, etc.).

The combination of Raman spectroscopy and LIBS could provide a more complete analysis in terms of mineralogy (e.g. chemical structure) and elemental composition. In this sense Lucey et al. ${ }^{144}$ have patented a spectrometer that combines remote Raman and LIBS capabilities in the same apparatus. This system is based on the fact that Raman and LIBS techniques interrogate samples using pulsed laser beams, but employing different irradiances (e.g.: 100-700 $\mathrm{mW} \mathrm{cm}^{-2}$ for Raman analysis and $>1 \mathrm{GW} \mathrm{cm}^{-2}$ for LIBS analysis). In order to simultaneously obtain the Raman and LIBS spectra, the developed system uses a focused laser that provides a central region of high irradiance for LIBS analysis and a peripheral region of lower irradiance for Raman analysis. A separate remote light collector is optically configurable to collect light emitted from the portion of the target emitting Raman scattering and from the portion of the target producing the plasma plume. Moreover, the collected signals are first passed through a filter to remove the reflected and Rayleigh-scattered light. This technology is of great interest for many applications, such as remote identification of explosives, explosive residue, chemical, minerals, gases, fumes, clouds, etc.

On the other hand, a new system based on the combination of laser ablation (LA) and LIBS has been patented by Hahn. ${ }^{145}$ In this system, a first laser beam pulse is used to ablate a target material. Then the ablation plume of target material is transported a sufficient distance away from the ablation event such that a second laser beam pulse can interact with it, creating an analytical plasma that is uncoupled from the ablation event. In this way, the atomization 
and excitation processes are separated in time and space, reducing the matrix effects associated to LIBS analysis. A similar device that uses two laser pulses along collinear paths (e.g. double-pulse LIBS) has been patented by Alexander et al. ${ }^{146}$ This method also includes shaping of the second pulse to have an annular distribution that could fit the annular particle cloud induced by the first laser pulse; and automation of the pulse delay using feedback information from the detected radiation to maximize the signal-to-noise ratio.

\subsection{Lasers as sources of intense monochromatic radiation}

\subsubsection{Laser atomic absorption}

A compact device based on the use of laser ablation to vaporize sample materials into a plume in which absorption spectra is measured using miniaturized tunable diode lasers, has been developed by Bol'shakova et al. ${ }^{147}$ to analyze key isotopic composition in surface materials without the need for sample preparation. This device, denominated Laser Ablation - Optical Cavity Isotopic Spectrometer (LAOCIS), has been designed to be employed in Mars rovers, and to be combined with cavity enhanced spectroscopy in order to boost the absorption sensitivity.

\subsubsection{Cavity Ringdown Spectroscopy (CRDS).}

In CRDS, light from a laser is sent to a ring-down cavity, which in its simplest form consists of a pair of high-reflectivity mirrors forming an optical cavity. When the laser is in resonance with a cavity mode, intensity builds up due to constructive interference. The laser is then turned off in order to allow measurement of the exponentially decaying light intensity due to both absorption and scattering by the medium within the cell and reflectivity losses. The cavity can thus be considered as a multi-pass cell with a huge optical path length, e.g. a few kilometers). The development of optical-feedback (OF)-CRDS, where a fraction of light leaking from the optical cavity is returned to the laser, enables high data acquisition rates and higher coupling efficiency of laser light into the cavity. OF-CRDS is one of the most sensitive methods to obtain absorption spectra of diluted gas samples and aerosols. A spectrometer based on OF-CRDS has been designed and evaluated by Tan et al. ${ }^{148}$. The laser is coupled to a V-shaped glass ceramic cavity, which creates an absorption path length greater than $2.8 \mathrm{~km}$, and resonance between the laser frequency and the cavity modes has been realized by modulating the cavity length instead of tuning the laser wavelength to obtain a higher resolution. 
Another approach is the use of the plasma-CRDS technique for sensitive elemental and isotopic measurements. Usually the plasma is used as an atomization source to generate atoms from injected compounds, however, Wang et al. ${ }^{149}$ have shown that the plasma can also be used as an electron impact excitation source, allowing the excitation of metastable states. The electron impact excitation-CRDS method (e.g. using $<10 \mathrm{eV}$ electrons generated in an atmospheric argon microwave plasma torch) has been employed to determine $\mathrm{Hg}$ at the $405 \mathrm{~nm}$ transition line. This method is an alternative way to measure $\mathrm{Hg}$ using a palm-size laser source, which could potentially lead to the development of a portable system.

\subsubsection{Laser-induced fluorescence (LIF).}

Noninvasive, laser-based spectroscopic techniques such as laser-induced fluorescence (LIF) are widely used for spatially and temporally resolved concentration measurements of intermediate species in chemically reacting flows (e.g. flames and plasmas). Multi-photon excitation is required for the measurement of key atomic species (e.g. $\mathrm{H}, \mathrm{O}$ and $\mathrm{N}$ ) as well as molecular species (e.g. CO). Wagenaars et al. ${ }^{150}$ have applied, for the first time, two-photon absorption LIF to measure atomic nitrogen species in a radio-frequency, atmospheric pressure, plasma jet operated in He- $\mathrm{N}_{2}$. This method allows the study of atomic nitrogen radicals, which are known to play a key role in new plasma medicine applications. However, multi-photon excitation might also produce photo-dissociation (photolysis) of molecular species, so in order to reduce this effect lasers with a shorter pulse duration have been evaluated. ${ }^{151}$ Nearly photolysis-free, two-photon LIF imaging of atomic hydrogen in flames, using a femtosecond laser, was demonstrated. Hydrogen is a key intermediate element in hydrocarbon combustion, its high reactivity and diffusivity making it important for ignition/extinction and heat release.

\section{$4 \quad$ Isotope Analysis}

Isotope analysis falls into two broad categories. Isotope dilution analysis (IDA) is a method used for quantification whereby an isotopically enriched spike of the analyte is added to the sample, and the modified isotopic ratios can be measured and used to determine the concentration of the analyte. Isotope ratio analysis (IRA) is used to obtain precise measurements of isotopic abundance, primarily for geochronology, isotope tracer studies and isotopic fingerprinting. This often involves novel developments in sample preparation and instrumentation. 


\subsection{Instrumentation.}

Ebata et al. ${ }^{152}$ describe a new nanobeam time-of-flight secondary neutral mass spectrometry technique which they prefer to call 'LIMAS'. This laser ionization mass nanoscope uses a gallium liquid metal ion source to generate a $40 \mathrm{~nm}$ primary beam sputtering the sample surface. Since the production of secondary ions during sputtering is an inefficient process (c.a. 1\%), a femtosecond laser was fired into the sample chamber to ionize the neutral species and increase the yield of the system by up to 100 times. Mass resolution approaching 40,000 was achievable and background was controlled by running at ultrahigh vacuum $\left(2 \times 10^{-8} \mathrm{~Pa}\right)$. It is anticipated that this instrument would lend itself to the analysis of nanosized particles returned from space missions. Newman ${ }^{153}$ considered unconventional effects on more conventional instrumentation by detailing the effects of novel sample and skimmer cone geometries in combination with enhanced interface pumping on a MC-ICP-MS. Sensitivity was doubled for the heavier elements using a sample cone with a large orifice (a so-called 'jet cone') while for the lighter elements (e.g. Li) enhanced pumping in combination with a standard sample cone provided better sensitivity. Instrumental mass discrimination effects on some elements, caused by the use of high-sensitivity skimmer cones, was also highlighted; the uncertainty surrounding the exact cause of these effects and how they are best corrected has implications for the accuracy of high precision data. The same author ${ }^{154}$ also compared the quality of data obtained using a new, rapid scanning single collector sector field (SC-SF)ICP-MS with equivalent data from a MC-ICP-MS using a multiple ion counting (MIC) array or a high-sensitivity Faraday set-up. The authors cite the difficulties with MIC arrays as: stability of the cross-calibration of ion yield; limited dynamic range; and potential to compromise the flexibility of the mass spectrometer if placed injudiciously within the Faraday array. Analysis of $\mathrm{Pb}$ isotopes in the CRM NBS981 illustrated the capability of the rapid-scanning SC-SF-ICP-MS, achieving long term uncertainties of $0.11 \%$ (2SD) for ${ }^{\mathrm{xxx}} \mathrm{Pb} /{ }^{206} \mathrm{~Pb}$ and $0.21-0.23 \%$ (2SD) for ${ }^{\mathrm{xxx}} \mathrm{Pb} /{ }^{204} \mathrm{~Pb}$ ratioa. The data were largely constrained by counting statistics, reflecting the speed of the electrostatic scanning as faster than the noise sources in the ICP. In addition, the method of scanning used avoided additional mass fractionation effects. A study of USGS rock reference materials, using sample-calibrator bracketing with dilution to cation concentrations $<10 \mu \mathrm{g} \mathrm{ml}^{-1}$ (or $<1.5 \mu \mathrm{g} \mathrm{m} l^{-1}$ for easily ionizable elements such as $\mathrm{Na}$ and $\mathrm{K}$ ), suggested matrix effects were negligible. For the analysis of waters however, where $\mathrm{Pb}$ concentrations are inherently low, significant matrix effects were apparent requiring that chemical purification of the $\mathrm{Pb}$ be performed to achieve 
accurate results. NanoSIMS is a promising technique for a number of applications. However, both Heister et al. ${ }^{155}$ and Hatton et al. ${ }^{156}$ lamented the lack of RMs certified at the spatial scale of nanoSIMS analyses for their respective studies of soil components and the carbon and nitrogen elemental and isotopic composition of soils.

Accordingly, the calibration materials were not representative of the sample material at the reduced scale of the analysis, so were unlikely to be truly accurate.

\subsection{Sample preparation}

A considerable number of papers demonstrate the renewed importance of high-quality chemical separation and purification methods for accurate isotope ratio measurements. Accurate, high-precision isotope ratio measurements generally require near-perfect chemical purification procedures for consistently high-quality data over the long-term. This is especially true for the analysis of the 'non-traditional' stable isotope systems and particularly lower mass elements, where the identification of mass-dependent fractionation is the goal and sample-calibration bracketing is often employed. High-quality chemical purification is also needed where the analyte is present at very low concentrations in the matrix.

Schiller et al. ${ }^{157}$ demonstrated that the exceptional can be achieved with time, effort and money. Using a 4-step, column separation procedure to achieve quantitative and pure $\mathrm{Ca}$ separations from silicate rocks, they were able to determine $\mathrm{Ca}$ isotopic compositions, including $\delta^{46} \mathrm{Ca}$ (which represents only $0.003 \%$ of $\mathrm{Ca}$ ), to very high precision, e.g. $1.8 \mathrm{ppm}$ (2 SE) for $\delta^{43} \mathrm{Ca}$, using HR-MC-ICP-MS. TIMS analyses were used to define $\delta^{40} \mathrm{Ca}$ to $80 \mathrm{ppm}$ (2SD) with the $\delta^{43} \mathrm{Ca}_{\text {TIMS }}$ uncertainty of $23 \mathrm{ppm}$ (2SD) highlighting the analytical gain that could be achieved using HR-MC-ICP-MS. This was attributed to increased ion beam size and analysis duration, variable fractionation on the TIMS filament, small differences in sample preparation, matrix and filament loading. This allowed a resolution of mass independent fractionation around 18-120 times (depending on the isotope ratio of interest) better than that achieved using TIMS alone. This enabled kinetic fractionation processes to be identified during biogenic and inorganic carbonate precipitation from seawater. Further, isotopic differences between SRM 915a and SRM 915b, led the authors to recommend the latter as the preferred reference material for $\mathrm{Ca}$ isotope determinations of rock samples. Mathew et al. ${ }^{158}$ improved the accuracy of the certified values for uranium isotope CRM U112a. Using a modified total evaporation (MTE) method they determined a new value of 137.849 for the ${ }^{238} \mathrm{U} /{ }^{235} \mathrm{U}$ composition of this material, improving the combined uncertainty to $551 \mathrm{ppm}$ 
$(\mathrm{k}=2)$. The ${ }^{234} \mathrm{U} /{ }^{238} \mathrm{U}$ ratio was additionally re-determined as $5.2841 \times 10^{-5}$, and the uncertainty improved to $0.1552 \%(\mathrm{k}=2)$, using a more conventional analytical routine and the new ${ }^{235} \mathrm{U} /{ }^{238} \mathrm{U}$ ratio for mass bias correction. The ${ }^{236} \mathrm{U} /{ }^{238} \mathrm{U}$ ratio was estimated to be $<5 \mathrm{x}$ $10^{-9}$. The composition of CRM145, the solution equivalent of the solid U112a, was also checked and confirmed to be statistically equivalent with no unit-to-unit variations, thereby establishing the homogeneity of both CRM's. TIMS was also the preferred method of Gautier et al. ${ }^{159}$ for the determination of the isotopic composition of ${ }^{76} \mathrm{Ge}$-enriched materials. They used a solid Ge powder sample loading method to avoid the need to quantitatively dissolve their material. Touboul and Walker ${ }^{160}$ described improved precision in the determination of ${ }^{182} \mathrm{~W}$ abundance in natural silicates. Using a 4-step chemical separation procedure and analysing the samples as $\mathrm{WO}_{3}{ }^{-}$using negative ion TIMS, an uncertainty of 4.5ppm (2SD) was achieved. This was after applying a correction for mass dependent oxygen isotope fractionation during the run. The uncertainty was quoted as 5 times more precise than conventional $\mathrm{W}$ measurements by $\mathrm{MC}-\mathrm{ICP}-\mathrm{MS}$, and allowed resolution of $10 \mathrm{ppm}$ differences in the ${ }^{182} \mathrm{~W} /{ }^{184} \mathrm{~W}$ composition of materials, as illustrated using ${ }^{182} \mathrm{~W}$ spiked reference materials. The ${ }^{182} \mathrm{~W}$ isobar on the radioisotope ${ }^{182} \mathrm{Hf}$ was a problem for Forstner et al. ${ }^{161}$ when investigating early solar system chronometry using AMS. They managed to increase the ${ }^{182} \mathrm{~W} /{ }^{182} \mathrm{Hf}$ suppression ratio 6-fold to 36000 by careful tuning of the ion source. They concluded that the major source of $\mathrm{W}$ interference was from the ion source itself rather than sample related, highlighting the importance of careful design of the ion source and selection of materials for construction and sputtering. Wang et al. ${ }^{162}$ used a collision-cell MC-ICP-MS to determine the isotopic composition of Se. Three highly enriched isotopes $\left({ }^{76} \mathrm{Se},{ }^{78} \mathrm{Se},{ }^{82} \mathrm{Se}\right)$ were gravimetrically mixed and used to calibrate seven natural Se materials including NIST SRM 3149, thereby allowing determination of the absolute isotopic composition of Se and a new atomic weight of $78.9711 \pm 0.0009(\mathrm{k}=2)$.

Other recent advances include the identification of new sample preparation procedures to improve variance in He isotope measurements ${ }^{163}$ and the isotopic determination of solar wind Xe implanted in Si targets flown on the Genesis mission. ${ }^{164}$ In the latter, Crowther and Gilmour used a $355 \mathrm{~nm}$ laser ablation system to liberate $\mathrm{Xe}$, finding the solar wind composition identical to that of lunar regolith samples irradiated by the solar wind in the last $100 \mathrm{Ma}$. This led them to conclude that the Earth's atmosphere is depleted in the heavy isotopes of Xe relative to the isotopic composition of solar wind Xe. Witte and Houk ${ }^{165}$ investigated the effect of adding nitrogen and helium to an ICP source on lowering the level 
of oxides produced and increasing the gas kinetic temperature of the plasma. This important work will further help understanding of plasma processes and the formation of polyatomic ions, and lead to improved data quality in both solution and laser ablation mode isotopic analyses by reducing and/or stabilising interferences in the mass spectrum, enabling better correction and resulting in lower data uncertainties. Contamination of biogenic Si samples with clays is an important issue in determining the oxygen isotope composition of the material. Chapligin et al. ${ }^{166}$ described a specious effect resulting from contamination of diatom samples with clays at the 0.1-1.5\% level. An initial apparent difference in the oxygen isotope composition between species characterising the size fractions above and below $10 \mu \mathrm{m}$ disappeared once correction was made for the small amount of clay in each. Although these calculations rely on mass balance calculations and the knowledge of the exact abundance and composition of the end-member clay component, the study serves to illustrate the effect of compositionally different contaminants or backgrounds no matter how small, and the importance of clean sample material in all forms of analysis for the reduction of 'interferences' in the mass spectrum.

Andersson and Schoberg ${ }^{167}$ demonstrated an effective procedure for separating Th, present in pmol kg-1 quantities, from seawater by modifying the best practices currently available for the separation of Th from other matrices. Using a ${ }^{229} \mathrm{Th}$ calibrated spike and iron oxyhydroxides to sequester the $\mathrm{Th}$ by precipitation from $3.5 \mathrm{~L}$ of seawater, they were able to obtain concentration uncertainties of $1-2 \%$ and $2-5 \%(2 \sigma)$ for the ${ }^{232} \mathrm{Th}$ and ${ }^{230} \mathrm{Th}$ respectively. Bio-Rad AG1-X8 and Eichrom TRU Resin and UTEVA Resin were used for purification and the samples were analysed using TIMS. Careful cleaning of the resins and selection of a graphite powder-based activator reduced the total procedural blank to $0.4 \mathrm{pg}$, which was $<1 \%$ of the typical ${ }^{232} \mathrm{Th}$ concentration in the sample, with only $10 \%$ of this identified as coming from the outgassed zone-refined Re filaments. With the low ionization efficiency of Th by TIMS, one wonders what more could be achieved by employing these practices while analysing the samples using MC-ICP-MS. In contrast, Auro et al. ${ }^{168}$ switched to Eichrom anion exchange resins rather than AG1-X8 to improve the Th blanks for their work on seawater, and also changed their column frit supplier to achieve greater recoveries. Additionally, they analysed the samples by MC-ICP-MS (using a mixed Th-Pa spike) and achieved a 1 y long-term uncertainty of $1.8 \%, 2.5 \%$ and $4.0 \%$ (2SD) for the ${ }^{232} \mathrm{Th},{ }^{230} \mathrm{Th}$ and ${ }^{231} \mathrm{~Pa}$ concentrations in a GEOTRACES seawater reference material. Despite these changes, total procedural blanks were around $7 \mathrm{pg}{ }^{232} \mathrm{Th}$, an order of magnitude worse than Andersson 
and Schoberg. Jeandel et al. ${ }^{169}$ advocated the use of Bio-Rad's AG1-X8 resin for the separation of $\mathrm{Ra}, \mathrm{Nd}$, $\mathrm{Th}, \mathrm{Pa}$ and $\mathrm{U}$ from natural samples including seawaters, using a single column extraction method, to improve efficiency, reduce sample size, increase throughput and ultimately reduce cost, but only achieved total procedural blanks of around $21 \mathrm{pg}$ for $\mathrm{Th}$, whereas blanks for other elements proved negligible. This range of approaches demonstrates the need for thorough scrutiny of fundamental methods when the quantification of small sample quantities and/or isotopic variation is the target. Without clean chemical preparation and low procedural blanks, isobaric interferences, peak tailing and correction uncertainty contributions will lead to inaccuracies and/or precision levels outside of the target range.

Other recent investigations into new chemical separation procedures included those by Grate et al. ${ }^{170}$ who utilised extraction chromatography followed by anion-exchange separations for the isolation of $\mathrm{Pu}$, while Marinov et al. ${ }^{171}$ used no separation chemistry at all in a process to enrich the super-heavy element Roentgenium by 3 to 4 orders of magnitude in gold. Biller and Bruland ${ }^{172}$ used a chelating resin to extract $\mathrm{Cd}, \mathrm{Co}, \mathrm{Cu}, \mathrm{Fe}, \mathrm{Mn}, \mathrm{Ni}, \mathrm{Pb}$ and $\mathrm{Zn}$ from seawater samples, and demonstrated quantitative recoveries using standard additions rather than isotope dilution. For some elements $(\mathrm{Co}$ and $\mathrm{Cu})$ it was necessary to perform UVoxidation prior to the extraction in order to determine accurate concentrations. The method was developed for high sample throughput with blank levels and detection limits appropriate for the study. The drive towards ever-increasing efficiency (read 'speed') with respect to 'labour intensive, time consuming and expensive' chemical separation procedures now sees robots entering the laboratory in the form of fully automated programmable micro-pipetting systems. A so-called 'columnspider' system is described by Miyazaki et al. ${ }^{173}$ as capable of eluting ten parallel samples in a single run once the resin columns, chemical reagents and collection beakers have been initially set-up by a human operator.

Complete chemical purification of the sample material is less critical when using IDA, but still highly preferable when ultra-high precision results are required. Gall et al. ${ }^{174}$ described a chemical separation and double-spike isotope dilution procedure which allowed determination of the isotopic composition of $\mathrm{Ni}$ with uncertainties of 70-140 ppm (2SD) about $35 \mathrm{ppm}$ for each mass unit difference in the ${ }^{\mathrm{xx}} \mathrm{Ni} /{ }^{58} \mathrm{Ni}$ ratio. The effectiveness of the separation procedure is claimed to be independent of $\mathrm{pH}$ and large matrix/analyte ratios, yielding pure processed solutions with between 85 and $95 \%$ recovery. A double-spike was required to correct for column-induced fractionation at lower recoveries. Data were reported 
for a number of USGS reference materials, analysed using MC-ICP-MS. Other double-spike applications illustrated this year include those for $\mathrm{Fe}$ and $\mathrm{Zn}$. Millet et al. ${ }^{175}$ combined a double-spike with sample-calibrant bracketing using HR-MC-ICP-MS to achieve a reproducibily of $20 \mathrm{ppm}(2 \mathrm{SD})$ for $\delta^{56} \mathrm{Fe}$ based on a data-set of 51 points acquired over 6 months. They went on to report new stable Fe isotope data for a number of international rock reference materials. Ghidan and Loss ${ }^{176}$ used double-spike ID to document separation column-induced fractionation of $70 \mathrm{ppm} \mathrm{amu}^{-1}$ in the isotope ratio for $\delta \mathrm{Zn}$ measurements using TIMS. Ionization efficiency from the TIMS filament was improved to $0.22 \%$ and double-spike determined $\mathrm{Zn}$ isotope data for a number of RMs were presented for the first time. Differences in the $\mathrm{Zn}$ isotopic composition of sedimentary versus metamorphic and/or igneous rocks were elucidated, conforming with the perceived notion that high pressure and temperature processes do not significantly fractionate the isotopic composition of chalcophile elements. Garcia-Ruiz et al. ${ }^{177}$ demonstrated the capability of single-spike ID to determine the concentration of $\mathrm{Cd}$ in natural waters at the new lower limit imposed by European legislation. Here, a miniaturised solid-phase extraction method was used to keep blanks low and the combined uncertainty was calculated as $3-4 \%(\mathrm{k}=2)$ for $\mathrm{Cd}$ concentrations around $100 \mathrm{ng} \mathrm{kg}^{-1}$.

\subsection{New applied developments}

\subsubsection{Nuclear forensics}

Nuclear safeguards and forensics is a growing area of isotope research. Full traceability to SI units and high quality measurements are key. Improvements in analytical methods, precision and the availability of CRMs has reduced the overall uncertainty that can be achieved when determining the $\mathrm{U}$ isotopic composition of materials. More recently, particle analysis has become the focus of capability investigations resulting in inter-laboratory comparison exercises NUSIMEP-6 and NUSIMEP-7. Burger et al. ${ }^{178}$ improved the performance of TIMS by applying the MTE method to the measurement of a series of RMs using a modern highperformance TIMS instrument. After chemical purification using $\mathrm{TOPO}^{\circledR}$ or $\mathrm{UTEVA}^{\circledR}$ resins, detection efficiencies (total number of atoms loaded vs those detected) of $0.005 \%$ and $0.03 \%$ were achieved for $\mathrm{U}$ and $\mathrm{Pu}$ respectively without emission enhancers. This approach decreased blanks and potential interferences enabling detection limits of $3 \times 10^{-9}$ for the ${ }^{236} \mathrm{U} /{ }^{238} \mathrm{U}$ ratio. An uncertainty of $22 \%(\mathrm{k}=2)$ was achieved for the reference material IRMM$075 / 5$ which has a certified value of $1 \times 10^{-8}$. Measurement uncertainties were improved 
using the MTE technique compared to the original total evaporation procedure, as well as by using an up to date mass spectrometer. However, in order to perform the MTE method a greater amount of sample material, around $2500 \mathrm{ng}$ of $\mathrm{U}$, was loaded onto the filament. Hydrides were demonstrated to contribute $<4 \times 10^{-7}$; this compares to ICP-MS measurements where $\mathrm{UH}^{+} / \mathrm{U}^{+}$is usually of the order of $3 \times 10^{-6}$. A comparison of NBL and IRMM CRM's was performed, which demonstrated equivalence between the two different sets of materials within the newly assigned uncertainties, while also recognising that the original uncertainty statements were rather over-cautious. Quality control procedures were described as well as the implementation of principles from the Guide to the Expression of Uncertainty in Measurements (GUM), allowing the comparison and quantification of the key contributing factors to the total uncertainty for the measurement of ${ }^{234} \mathrm{U} /{ }^{238} \mathrm{U},{ }^{235} \mathrm{U} /{ }^{238} \mathrm{U}$ and ${ }^{236} \mathrm{U} /{ }^{238} \mathrm{U}$ ratios in a number of key reference materials spanning the compositional range from depleted to highly enriched uranium. Shinonaga et al. ${ }^{179}$ have demonstrated a method (and some of the difficulties) to produce plutonium dioxide particles for quality control measurements in nuclear safeguards investigations. Particles of 0.4-1.4 $\mu \mathrm{m}$ in size were produced from CRM-136, an NBL Pu RM, using an atomiser system. They determined the $\mathrm{Pu}$ and $\mathrm{U}$ isotopic composition of the particles by TIMS and SF-ICP-MS, the amount of U and Am by ICP-MS, and uncertainties were quantified using GUM principles. An alternative method for particle analysis is fission-track SIMS. Esaka et al. ${ }^{180}$ described a preparation technique for particle analysis by SIMS after locating the particles via their fission-tracks in a polycarbonate film. When applied to real-world, swipe samples, with c.a. $2 \mu \mathrm{m}$ sized particles, the use of initial particle characterisation using the fission-track technique expanded the range of compositions determined by SIMS compared to a previous exercise where the particles had been mounted and analysed directly without recourse to their fission-track characteristics. This method of preparation appears to enhance capability for identifying higher enriched uranium particles in a sample population. A more recent method of uranium particle analysis was illustrated by Pointurier et al. ${ }^{181}$ who used Q-ICP-MS and a $213 \mathrm{~nm}$ laser ablation system to target sub-micron particles in order to achieve the required capability, in terms of throughput and cost, necessary for analysing particles for nuclear safeguards and forensics. Samples were mounted on disks using collodion after particle location by SEM or the fission-track method. Experiments were undertaken using the NUSIMEP-6 interlaboratory comparison sample, and detection efficiency was quantified at $0.06 \%$ for the $0.2-$ $0.3 \mu \mathrm{m}$ particles which were calculated to contain 14-48 fg of $\mathrm{U}$, corresponding to $0.1-0.33 \mathrm{fg}$ of ${ }^{235} \mathrm{U}$ ! The small amounts of $\mathrm{U}$ and nature of the instrumentation used resulted in 
uncertainties for the ${ }^{235} \mathrm{U} /{ }^{238} \mathrm{U}$ ratio of $20-25 \% \quad(\mathrm{k}=1)$. Using multi-collector mass spectrometers and more up-to-date laser ablation technology could improve the signal to noise ratio of this method and enable LA-ICP-MS to be a viable tool for the nuclear safeguards and forensics community. Huber et al. ${ }^{182}$ used laser induced desorption (LID), laser induced ablation (LIA) and laser induced breakdown (LIB) spectroscopies to investigate the amount of tritium retained on the walls of fusion devices. LIDS, in combination with alpha spectroscopy, was considered to be a reliable technique for the purpose, whereas LIAS and LIBS were still under investigation for determining the thickness and composition of the deposited layer. LIBS was also the focus for Cremers et al. ${ }^{138}$ who were attempting to develop a field-deployable system capable of measuring the isotopic composition of $\mathrm{H}, \mathrm{Li}, \mathrm{U}$ and $\mathrm{Pu}$. They combined a hand-held LIBS probe with a high-resolution mass spectrometer and successfully detected $\mathrm{U}$ and $\mathrm{H}$ isotopes, and discriminated between ${ }^{6} \mathrm{Li}$ and ${ }^{7} \mathrm{Li}$.

A number of isotope half-lives have been re-determined. Nedjadi et al. ${ }^{183}$ purified ${ }^{166} \mathrm{Ho}$ to reduce the isobar caused by Er and determined a half-life of 1133 y using ID-MC-ICP-MS. This was claimed to be $5.6 \%$ shorter than previously determined and 43 times more precise. He et al. ${ }^{184}$ used MC-ICP-MS and gamma-ray spectrometry (for activity) to determine the half-life of ${ }^{94} \mathrm{Nb}$, and achieved a 4-fold improvement in precision. Jorg et al. ${ }^{185}$ achieved a 3fold improvement in the uncertainty of the ${ }^{41} \mathrm{Ca}$ half-life, compared to more recent estimates, by combining liquid scintillation counting and ID-TIMS. This has applications in nuclear waste studies and in defining the chronology of the solar system. Rotenberg et al. ${ }^{186}$ have re-defined the half-life of ${ }^{87} \mathrm{Rb}$ by utilising the lab accumulation of ${ }^{87} \mathrm{Sr}$ over a 30 year period. They measured the Sr isotopic composition using ID-TIMS and a specially prepared ${ }^{84} \mathrm{Sr}-{ }^{86} \mathrm{Sr}$ double spike, but still found a scatter in the determined decay constant values. The new value of $49624(+65,-95) \mathrm{Ma}\left(\lambda^{87} \mathrm{Rb}=1.3968(+0.0027-0.0018) \times 10^{-11} \mathrm{a}^{-1}\right)$ agreed with nearly all determined values since 1977, but improves the uncertainty while conceding that some uncertainty components are yet to be recognised. On the basis of agreement between multiple determinations using multiple methods, they argue that the $\mathrm{Rb}-\mathrm{Sr}$ chronometer is now one of the best constrained chronometers available and should take its rightful place alongside the $\mathrm{U}-\mathrm{Pb}$ and $\mathrm{Ar}-\mathrm{Ar}$ geochronometers in the EARTHTIME initiative to better calibrate the geological timescale.

\subsubsection{Geochronology}


The study of geochronology, for both its application and fundamental development, is ever popular and has seen increasing focus on isotope systems for researching stellar and planetary evolution. Paton et al. ${ }^{187}$ used very high precision MC-ICP-MS measurements, coupled with a modified ID approach, to improve the determination of ${ }^{27} \mathrm{Al} /{ }^{26} \mathrm{Mg}$ ratios, which is a limiting factor in the precision of the ${ }^{26} \mathrm{Al}-{ }^{26} \mathrm{Mg}$ geochronometer used for early solar system research. Unpurified samples were measured both with and without a well calibrated ${ }^{25} \mathrm{Mg}^{27} \mathrm{Al}$ mixed spike thereby negating the effect of matrix-induced bias. Using rock reference materials and a gravimetrically prepared Al-Mg reference solution an accuracy of $0.2 \%$ was achieved. This represented a significant improvement in uncertainty (up to an order of magnitude) compared to previous studies and propagates an equivalent improvement in the resolution of the chronometer. Some of the same authors ${ }^{188}$ demonstrated the application of this new method to resolve deficits as small as $0.005 \%$ in the ${ }^{26} \mathrm{Mg}$ content of sub-chondritic meteorites. These were hypothesised to exhibit up to a maximum of $0.037 \%$ deviation in the ${ }^{26} \mathrm{Mg} /{ }^{24} \mathrm{Mg}$ ratio (expressed as $\delta^{26} * \mathrm{Mg}$ ) as a result of the absence of the short-lived ${ }^{26} \mathrm{Al}$ isotope which would otherwise have decayed to ${ }^{26} \mathrm{Mg}$ over the first $2 \mathrm{Ma}$ after solar system formation. The same group ${ }^{189}$ investigated the ${ }^{176} \mathrm{Lu}^{176} \mathrm{Hf}$ decay system using the same instrumentation in order to highlight excess ${ }^{176} \mathrm{Hf}$ anomalies in chondrite meteorites, equating to a c.a. $300 \mathrm{Ma}$ excess in apparent age. The resolution of this, and the impact on the interpretation of Hf isotope data, has important implications for the timing of the onset of plate tectonics early in Earth's history. Vermeesch et al. ${ }^{190}$ have reported a simplified method for in-situ U-Th-He dating. This used the measured ${ }^{208} \mathrm{~Pb} /{ }^{206} \mathrm{~Pb}$ ratio for the reference zircon as a monitor of the $\mathrm{Th} / \mathrm{U}$ ratio, thereby obviating the need for calibration using NIST glass or another interelemental monitor, and calculated the normalised concentrations from the known U-Th-He age. These were then scaled to the measured isotope signals from the sample, thereby requiring no knowledge of the absolute elemental concentrations of each element. The variation in the stoichiometric ${ }^{29} \mathrm{Si}$ isotope was used as a proxy for the variation of drill rate and the data corrected accordingly. Chu et al. ${ }^{191}$ found that up to $10 \%$ of the $\mathrm{Sm}$ and $\mathrm{Nd}$ content of scheelite could be retained in the tungstic acid precipitate formed from the mineral while using a typical low-temperature dissolution method. Although absent during PTFE bomb dissolution, this precipitate could be dissolved by a further $\mathrm{NaOH}$ dissolution step, thereby allowing an easier method to achieve complete spike-sample equilibration for highprecision scheelite dating. Rutile is an increasingly important mineral for geochronology and a number of new methods have been proposed for its dating. Taylor et al. ${ }^{192}$ combined electron back-scattering diffraction and SIMS to demonstrate grain orientation effects on the 
$\mathrm{U} / \mathrm{Pb}$ ratio determined by the latter method. This effect resulted in a calibration slope which was an order of magnitude greater than for other minerals not showing this effect. The authors proposed an analytical protocol involving the collection of reference data in multiple crystallographic orientations to overcome this problem.

\subsubsection{Environmental and bioanalytical science}

After recent improvements in the analysis of Ge isotopes, the research community have collaborated on an inter-laboratory study to redefine approaches and improve data intercomparison. ${ }^{193}$ They have defined a new delta-zero reference material for Ge in an existing CRM of ready supply (NIST SRM 3120a), settled on a common delta notation form $\left({ }^{\mathrm{x}} \mathrm{Ge} /{ }^{70} \mathrm{Ge}\right)$ with $\delta^{74} \mathrm{Ge}$ being the main reported value, agreed on best practice methods of characterisation and correction of their data (e.g. hydrides), and generally striven to improve the lot of the Ge isotope geochemist. Inter-calibration has been demonstrated through rock and meteorite samples using MC-ICP-MS (both single and double focussing) with or without hydride generation as appropriate, using external bracketing, with or without internal mass bias correction using a Ga dopant, and double spiking. The average reproducibility reported was $0.15 \%(2 \sigma)$. Bulk silicate earth (BSE) $\delta^{74} \mathrm{Ge}$ was redefined as $0.59 \pm 0.18(2 \sigma)$ relative to the new delta-zero reference, and strong heavy isotope depletion in geological ore materials was noted which is consistent with theoretical fractionation behaviour. A similar exercise was attempted for $\mathrm{Cl}$ isotopes ${ }^{194}$ as a benchmarking exercise for this difficult analytical challenge. Improvements in the validation and quality control of boron isotope data was the target for Vogl and Rosner ${ }^{195}$, who described the production and certification of new delta reference materials enriched in either ${ }^{10} \mathrm{~B}$ or ${ }^{11} \mathrm{~B}$. The CRMs ERM-AE102a, 104a, 120, 121 and 122, which cover the $\delta^{11} \mathrm{~B}$ compositional range $(-20.2$ to $+39.7 \pm 0.6, \mathrm{k}=2)$ of c.a.75\% of the known natural B isotope variation, were tested for stability and homogeneity. New CRM's for $\mathrm{Cu}$ and $\mathrm{Zn}$ have also been reported. Moeller and colleagues ${ }^{196}$ cross calibrated their diminishing stocks of the no-longer available NIST SRM976 (Cu) and JMC Lyon $(\mathrm{Zn})$ reference materials with the new ERM-AE633 and $647(\mathrm{Cu})$ and IRMM-3702 $(\mathrm{Zn})$ equivalents. This allowed continuous and reliable comparison of new with old data, and traceability to the SI for $\mathrm{Zn}$ isotope measurements. The CRM NIST SRM976 (Cu) was redefined as $-0.01 \pm 0.05$ and $-0.21 \pm 0.05(\mathrm{k}=2$, relative to ERM-AE633 and 647 respectively) and JMC Lyon $(\mathrm{Zn})$ as $-0.29 \pm 0.05(\mathrm{k}=2$, relative to IRMM-3702). Five rock reference materials were purified and analysed using MC-ICP-MS with calibrant-sample bracketing and internal $\mathrm{Ni}$ doping for $\mathrm{Cu}$ isotopes, and double-spiking for $\mathrm{Zn}$ isotopes. Good 
agreement was reported with literature values. This improved metrology for $\mathrm{Cu}-\mathrm{Zn}$ will be useful to a number of new research areas, including that described by Jaouen et al. ${ }^{197}$ who reported results of applying new $\mathrm{Fe}, \mathrm{Cu}$ and $\mathrm{Zn}$ isotope measurements to archaeological bones, in an attempt to discriminate the sex of the individual. Blood $\mathrm{Fe}$ and $\mathrm{Cu}$ isotopes show discrimination between male and female blood so it was hypothesised that bones should show the same trend because bones reflect the composition of blood. Analysis of samples, already gender characterised by traditional methods, was undertaken using MC-ICP-MS and 77\% of the samples were correctly identified (c.f. $81 \%$ by blood characterisation), with $\mathrm{Fe}$ and $\mathrm{Cu}$ isotopes being discriminatory whereas $\mathrm{Zn}$ isotope ratios were not. This would seem to provide a useful means of assigning gender to incomplete remains. Carbon and nitrogen isotopes have been utilised forensically ${ }^{198}$ to successfully fingerprint 65 cyanide samples, showing a false match rate of $<3 \%$. Seawater has been suggested ${ }^{199}$ as a new source of reference material for Mg isotopes. Using MC-ICP-MS, 40 samples from the Gulf of Mexico showed vertical and lateral homogeneity and compared favourably with 50 other data for seawater samples collected worldwide, with $\delta^{26} \mathrm{Mg}$ averaging $-0.83 \pm 0.11$ (2SD). This suggests a long $\mathrm{Mg}$ residence time in the oceans of around $13 \mathrm{Ma}$. With this composition being near the middle of the natural range of variation, seawater is potentially an excellent $\delta^{26} \mathrm{Mg}$ reference material for validation of analytical protocols and should prove useful for studying the isotope systematics of calcium carbonate precipitation. Similarly, Gabitov et $a l .{ }^{200}$ investigated the fractionation of oxygen isotopes during the growth of a calcite crystals by adding REE to the growing media of single crytals. Carbonate $\delta^{18} \mathrm{O}$ is considered as a temperature indicator, but contrasting results obtained from experiments and natural materials suggest that the existence of chemical equilibrium in nature cannot always be assumed. Measurements of stable isotope ratios, by IRMS on the bulk carbonate and experimental fluid, overlapped within their uncertainty with average of SIMS data, thereby validating the SIMS results. However, individual SIMS measurements revealed a decrease in $\delta^{18} \mathrm{O}$ by up to $1.5 \%$ as the growth rate increased. This suggests that $\delta^{18} \mathrm{O}$ was depleted close to the crystallisation front where rapid crystal could capture the depleted isotopic signature. Consideration of growth rate is therefore important when using $\delta^{18} \mathrm{O}$ in carbonates as a temperature proxy. A similar method was used by Brahmi and co-workers ${ }^{201}$ who demonstrated a method for labelling marine biocarbonate by doping seawater with a ${ }^{86} \mathrm{Sr}$ spike for 48 hour periods separated by 5 days of growth in a normal seawater composition. This was repeated three times and nano-SIMS was used to construct ${ }^{86} \mathrm{Sr} /{ }^{44} \mathrm{Ca}$ maps at the sub- $\mu \mathrm{m}$ scale to record the ultrastructural details and growth histories of scleractinian corals. 
The authors noted that this method could also be applied to studies of shells, tests, spines and other biocarbonate materials. Elemental and isotopic mapping of bio-materials is a growing area of research. Paul et al. ${ }^{202}$ demonstrated a new software method for integrating laser positional data with analytical data from the mass spectrometer to construct a map of the analytical data. Flexible integration allows the constructed maps to be overlain onto other data sets (e.g. optical microscopy, SEM or CL imaging data) and this was demonstrated using a sample of fish otolith to provide information on migration patterns. This kind of knowledge is gathering importance now as food security and conservation of key nutritional resources, such as protein from fish, becomes high on the agenda of world governments. McMahon and co-workers $^{203,204}$ detailed a new method using the carbon isotope signature of the amino acids extracted from fish otoliths to elucidate the residency of fish during their juvenile and adult stages. Compared to bulk stable isotope analysis, compound specific $\delta^{13} \mathrm{C}$ analysis of the otolith and muscle amino acids varied with habitat type. This also indicated that microbially recycled detrital carbon was the carbon source rather than new carbon from phytoplankton in the water-column, at least in one study area. These kinds of bioanalytical data are critical for marine conservation issues and the identification and designation of key protected areas. Chemometrics was used by Ariyama et al. ${ }^{205}$ in a 10 -fold cross-validation exercise, for a similar food security issue, this time to identify the origin of rice sold in Japan. Isotopes of $\mathrm{Sr}$ and $\mathrm{Pb}$, as well as elemental geochemistry, were combined to give $97 \%$ accuracy in discriminating between native samples and those from China, USA and Thailand.

\section{Glossary of Abbreviations}

Whenever suitable, elements may be referred to by their chemical symbols and compounds by their formulae. The following abbreviations may be used without definition. Abbreviations also cover the plural form.

$\begin{array}{ll}\text { AA } & \text { atomic absorption } \\ \text { AAS } & \text { atomic absorption spectrometry } \\ \text { AMS } & \text { accelerator mass spectrometry } \\ \text { APDC } & \text { ammonium pyrrolidine dithiocarbamate } \\ \text { CCD } & \text { charge coupled detector } \\ \text { CCP } & \text { capacitively coupled plasma } \\ \text { CVG } & \text { chemical vapour generation } \\ \text { DFA } & \text { discriminant function analysis } \\ \text { DLLME } & \text { dispersive liquid-liquid microextraction } \\ \text { DMA } & \text { dimethylarsinic acid }\end{array}$


ETAAS

EtHg

EVG

FAAS

GD

HG

iCCD

ICP-AFS

ICP-MS

ICR

IDA

IL

IMS

ITER

LA

LAOCIS

lasso

LEAFS

LEI

LEP

LIBS

LIF

LIF

LIPS

LLE

LOV

LOD

LOQ

LTE

MALDI

MB-PLS

MC-ICP-MS

$\mathrm{MeHg}$

MIP-AES

$\mathrm{n}_{\mathrm{e}}$

NIR

NP

OF

PCR

PLS

PVG

QC

QF-AAS electrothermal atomic absorption spectrometry

ethylmercury

electrochemical vapour generation

flame atomic absorption spectrometry

glow discharge

hydride generation

intensified charge coupled device

inductively coupled plasma atomic fluorescence spectrometry

inductively coupled plasma mass spectrometry

ion cyclotron resonance

Isotope dilution analysis

ionic liquid

ion mobility spectrometry

International Thermonuclear Experimental Reactor

laser ablation

Laser Ablation - Optical Cavity Isotopic Spectrometer

least absolute shrinkage and selection operator

laser-excited atomic fluorescence spectrometry

laser-enhanced ionization

liquid electrode plasma

laser induced breakdown spectroscopy

laser-induced fluorescence

laser induced fluorescence

laser induced plasma spectroscopy

liquid liquid extraction

lab-on-a-valve

limit of detection

limit of quantification

local thermodynamic equilibrium

matrix-assisted laser desorption ionization

multi-block partial least squares

multi-collector inductively coupled plasma mass spectrometry

methyl mercury

microwave induced plasma atomic emission spectrometry

electron number density

near infrared

nano particle

optical feedback

principal components regression

partial least squares

photochemical vapour generation

quality control

quartz furnace atomic absorption spectrometry 


$\begin{array}{ll}\text { Q-ICP-MS } & \text { quadrupole inductively coupled plasma mass spectrometry } \\ \text { RDC } & \text { ring-down cavity } \\ \text { RSD } & \text { relative standard deviation } \\ \text { SD } & \text { standard deviation } \\ \text { SDME } & \text { single-drop microextraction } \\ \text { SF-ICP-MS } & \text { sector-field inductively coupled plasma mass spectrometry } \\ \text { SIMS } & \text { secondary ion mass spectrometry } \\ \text { SPE } & \text { solid phase extraction } \\ \text { S-PLS } & \text { serial partial least squares } \\ \mathrm{T}_{\text {exc }} & \text { excitation temperature } \\ \mathrm{T}_{\text {gas }} & \text { gas temperature } \\ \mathrm{T}_{\text {ion }} & \text { ionization temperature } \\ \text { TIMS } & \text { thermal ionization mass spectrometry } \\ \text { TOF-MS } & \text { time-of-flight mass spectrometry } \\ \mathrm{T}_{\text {rot }} & \text { rotational temperature } \\ \text { VUV } & \text { vacuum ultraviolet }\end{array}$

\section{6. $\quad$ References}

1 S. Carter, A. S. Fisher, P. S. Goodall, M. W. Hinds, S. Lancaster and S. Shore, J. Anal. At. Spectrom., 2011, 26(12), 2319-2372.

2 O. T. Butler, W. R. L. Cairns, J. M. Cook and C. M. Davidson, J. Anal. At. Spectrom., 2012, 27(2), 187-221.

3 A. Taylor, M. P. Day, J. Marshall, M. Patriarca and M. White, J. Anal. At. Spectrom., 2012, 27(4), 537-576.

4 E. H. Evans, C. D. Palmer and C. M. M. Smith, J. Anal. At. Spectrom., 2012, 27(6), 909-927.

5 R. Clough, L. R. Drennan-Harris, C. F. Harrington, S. J. Hill and J. F. Tyson, J. Anal. At. Spectrom., 2012, 27(8), 1185-1224.

6 M. West, A. T. Ellis, P. J. Potts, C. Streli, C. Vanhoof, D. Wegrzynek and P. Wobrauschek, J. Anal. At. Spectrom., 2012, 27(10), 1603-1644.

7 D. Das, M. Dutta, M. L. Cervera and M. de la Guardia, Trac-Trends Anal. Chem., 2012, 33(35-45.

8 L. Kocurova, I. S. Balogh, J. Sandrejova and V. Andruch, Microchem. J., 2012, 102(11-17.

9 A. Jain and K. K. Verma, Anal. Chim. Acta, 2011, 706(1), 37-65.

10 X. W. Zhao, N. Z. Song, W. H. Zhou and Q. Jia, Cent. Eur. J. Chem, 2012, 10(4), 927-937.

11 K. Pyrzynska, Anal. Chim. Acta, 2012, 741(9-14.

12 M. F. Mesko, C. A. Hartwig, C. A. Bizzi, J. S. F. Pereira, P. A. Mello and E. M. M. Flores, Int. J. Mass spectrom., 2011, 307(1-3), 123-136.

13 Y. Wang, X. Y. Luo, J. Tang, X. Y. Hu, Q. Xu and C. Yang, Anal. Chim. Acta, 2012, 713(92-96. 
14 N. Zhang and B. Hu, Anal. Chim. Acta, 2012, 723(54-60.

15 Y. K. Tsoi, Y. M. Ho and K. S. Y. Leung, Talanta, 2012, 89(162-168.

16 E. Shamaeli and N. Alizadeh, Anal. Sci., 2012, 28(2), 153-158.

17 P. H. Pacheco, R. A. Gil, S. E. Cerutti, P. Smichowski and L. D. Martinez, Talanta, 2011, 85(5), 2290-2300.

18 X. Z. Cheng, J. Liu, X. L. Yang, H. M. Chen and Y. R. Wang, At. Spectrosc., 2011, 32(5), 175-181.

19 X. Z. Cheng, K. Shao, S. Y. Shen, S. H. Hu and H. O. Qiu, Geostand. Geoanal. Res., 2011, 35(4), 461-469.

20 F. Cacho, L. Lauko, A. Manova and E. Beinrohr, J. Anal. At. Spectrom., 2012, 27(4), 695-699.

21 V. Vickackaite and A. Padarauskas, Cent. Eur. J. Chem, 2012, 10(3), 652-674.

22 M. D. Joshi and J. L. Anderson, Rsc Advances, 2012, 2(13), 5470-5484.

23 L. Ranjbar, Y. Yamini, A. Saleh, S. Seidi and M. Faraji, Microchim. Acta, 2012, 177(1-2), 119-127.

24 P. Berton, E. M. Martinis, L. D. Martinez and R. G. Wuilloud, Anal. Chim. Acta, 2012, 713(56-62.

25 C. G. Yuan, P. Liang and Y. Y. Zhang, Microchim. Acta, 2011, 175(3-4), 333339.

26 G. Absalan, M. Akhond, L. Sheikhian and D. M. Goltz, Analytical Methods, 2011, 3(10), 2354-2359.

27 E. M. Martinis, L. B. Escudero, P. Berton, R. P. Monasterio, M. F. Filippini and R. G. Wuilloud, Talanta, 2011, 85(4), 2182-2188.

28 D. Iwahata, M. Tsuda, T. Aigaki and H. Miyano, J. Anal. At. Spectrom., 2011, 26(12), 2461-2466.

29 Y. R. Tang, X. Jiao, R. Liu, L. Wu, X. D. Hou and Y. Lv, J. Anal. At. Spectrom., 2011, 26(12), 2493-2499.

30 D. Kretschy, M. Groger, D. Zinkl, P. Petzelbauer, G. Koellensperger and S. Hann, Int. J. Mass spectrom., 2011, 307(1-3), 105-111.

31 D. Kretschy, G. Koellensperger and S. Hann, Metallomics, 2011, 3(12), 13041309.

32 Y. Li, S. K. Sun, J. L. Yang and Y. Jiang, Analyst, 2011, 136(23), 5038-5045.

33 P. Jarujamrus, R. Chawengkirttikul, J. Shiowatana and A. Siripinyanond, J. Anal. At. Spectrom., 2012, 27(5), 884-890.

34 Y. L. Yu, Y. Jiang, M. L. Chen and J. H. Wang, Trac-Trends Anal. Chem., 2011, 30(10), 1649-1658.

35 R. Rodriguez, J. Avivar, L. Ferrer, L. O. Leal and V. Cerda, Talanta, 2012, 96(96-101.

36 C. K. Su, Y. L. Lin and Y. C. Sun, J. Anal. At. Spectrom., 2012, 27(1), 56-62.

37 J. Avivar, L. Ferrer, M. Casas and V. Cerda, J. Anal. At. Spectrom., 2012, 27(2), 327-334.

38 S. O. Klemm, A. A. Topalov, C. A. Laska and K. J. J. Mayrhofer, Electrochem. Commun., 2011, 13(12), 1533-1535.

39 S. O. Klemm, A. Karschin, A. K. Schuppert, A. A. Topalov, A. M. Mingers, I. Katsounaros and K. J. J. Mayrhofer, J. Electroanal. Chem., 2012, 677(50-55. 
40 R. Sanchez, J. L. Todoli, C. P. Lienemann and J. M. Mermet, J. Anal. At. Spectrom., 2012, 27(6), 937-945.

41 J. W. Olesik and P. J. Gray, J. Anal. At. Spectrom., 2012, 27(7), 1143-1155.

42 H. E. Pace, N. J. Rogers, C. Jarolimek, V. A. Coleman, C. P. Higgins and J. F. Ranville, Anal. Chem., 2011, 83(24), 9361-9369.

43 B. Franze, I. Strenge and C. Engelhard, J. Anal. At. Spectrom., 2012, 27(7), 1074-1083.

44 D. M. Mitrano, E. K. Lesher, A. Bednar, J. Monserud, C. P. Higgins and J. F. Ranville, Environ. Toxicol. Chem., 2012, 31(1), 115-121.

45 M. S. Jimenez, M. T. Gomez, E. Bolea, F. Laborda and J. Castillo, Int. J. Mass spectrom., 2011, 307(1-3), 99-104.

46 D. M. Mitrano, A. Barber, A. Bednar, P. Westerhoff, C. P. Higgins and J. F. Ranville, J. Anal. At. Spectrom., 2012, 27(7), 1131-1142.

47 E. Bolea, J. Jimenez-Lamana, F. Laborda and J. R. Castillo, Anal. Bioanal. Chem., 2011, 401(9), 2723-2732.

48 E. A. Kapellios and S. A. Pergantis, J. Anal. At. Spectrom., 2012, 27(1), 21-24.

49 R. Umehara, H. Miyahara, A. Okino, M. Harada and T. Okada, Anal. Sci., 2012, 28(4), 359-365.

50 S. A. Pergantis, T. L. Jones-Lepp and E. M. Heithmar, Anal. Chem., 2012, 84(15), 6454-6462.

51 V. Geertsen, P. Lemaitre, M. Tabarant and F. Chartier, J. Anal. At. Spectrom., 2012, 27(1), 146-158.

52 H. Y. Cheng, Z. G. Xu, J. H. Liu, X. Z. Wang and X. F. Yin, J. Anal. At. Spectrom., 2012, 27(2), 346-353.

53 H. Y. Cheng, J. H. Liu, X. F. Yin, H. Shen and Z. G. Xu, Analyst, 2012, 137(13), 3111-3118.

54 Y. Takasaki, K. Inagaki, A. Sabarudin, S. I. Fujii, D. Iwahata, A. Takatsu, K. Chiba and T. Umemura, Talanta, 2011, 87(24-29.

55 Y. Takasaki, S. Sakagawa, K. Inagaki, S. I. Fujii, A. Sabarudin, T. Umemura and H. Haraguchi, Anal. Chim. Acta, 2012, 713(23-29.

56 S. N. Hanna and B. T. Jones, ApSRv, 2011, 46(8), 624-635.

57 S. N. Hanna, J. Keene, C. P. Calloway and B. T. Jones, Instrum. Sci. Technol., 2011, 39(4), 345-356.

58 S. N. Hanna, C. P. Calloway, J. D. Sanders, R. A. Neslon, J. Cox and B. T. Jones, Microchem. J., 2011, 99(2), 165-169.

59 P. Foltynova, V. Kanicky and J. Preisler, Anal. Chem., 2012, 84(5), 2268-2274.

60 A. Asfaw and D. Beauchemin, J. Anal. At. Spectrom., 2012, 27(1), 80-91.

61 A. Asfaw, W. R. MacFarlane and D. Beauchemin, J. Anal. At. Spectrom., 2012, 27(8), 1254-1263.

62 S. Z. Chen and D. B. Lu, At. Spectrosc., 2012, 33(1), 9-13.

63 Y. Z. Yi, S. J. Jiang and A. C. Sahayam, J. Anal. At. Spectrom., 2012, 27(3), 426-431.

64 Z. Long, Y. M. Luo, C. B. Zheng, P. C. Deng and X. D. Hou, ApSRv, 2012, 47(5), 382-413.

65 Z. Long, C. Chen, X. D. Hou and C. B. Zheng, ApSRv, 2012, 47(7), 495-517.

66 H. Matusiewicz and R. E. Sturgeon, ApSRv, 2012, 47(1), 41-82. 
67 H. Matusiewicz and M. Slachcinski, Microchem. J., 2012, 102(61-67.

68 J. Kratzer, B. Docekal, U. Heitmann and J. Dedina, J. Anal. At. Spectrom., 2011, 26(11), 2230-2237.

69 E. Henden, Y. Islek, M. Kavas, N. Aksuner, O. Yayayuruk, T. D. Ciftci and R. Ilktac, Spectrochim. Acta Pt. B-Atom. Spectrosc., 2011 , 66(11-12), 793-798.

70 E. Pagliano, M. Onor, J. Meija, Z. Mester, R. E. Sturgeon and A. D'Ulivo, Spectrochim. Acta Pt. B-Atom. Spectrosc., 2011, 66(9-10), 740-747.

71 E. M. Becker, M. B. Dessuy, W. Boschetti, M. G. R. Vale, S. L. C. Ferreira and B. Welz, Spectrochim. Acta Pt. B-Atom. Spectrosc., 2012, 71-72(102-106.

72 L. L. Chaparro, L. Ferrer, V. Cerda and L. O. Leal, Anal. Bioanal. Chem., 2012, 404(5), 1589-1595.

73 D. Y. Deng, J. R. Zhou, X. Ai, L. Yang, X. D. Hou and C. B. Zheng, J. Anal. At. Spectrom., 2012, 27(2), 270-275.

74 C. J. Zeng, N. Zhou and J. W. Luo, J. Anal. At. Spectrom., 2012, 27(1), 120125.

75 S. Cerutti, L. A. Escudero, J. A. Gasquez, R. A. Olsina and L. D. Martinez, J. Anal. At. Spectrom., 2011, 26(12), 2428-2433.

76 M. Saenz, L. Fernandez, J. Dominguez and J. Alvarado, Spectrochim. Acta Pt. B-Atom. Spectrosc., 2012, 71-72(107-111.

77 W. B. Zhang, X. A. Yang, J. J. Xue and S. B. Wang, J. Anal. At. Spectrom., 2012, 27(6), 928-936.

78 M. H. Arbab-Zavar, M. Chamsaz, A. Youssefi and M. Aliakbari, Talanta, 2012, 97(229-234.

79 M. H. Arbab-Zavar, M. Chamsaz, A. Youssefi and M. Aliakbari, Anal. Sci., 2012, 28(7), 717-722.

80 Q. H. Yang, W. E. Gan, Y. Deng and H. H. Sun, Spectrochim. Acta Pt. B-Atom. Spectrosc., 2011, 66(11-12), 855-860.

81 M. K. Sengupta and P. K. Dasgupta, Anal. Chem., 2011, 83(24), 9378-9383.

82 M. Masrournia and R. Shadmehri, Toxicol. Environ. Chem., 2011, 93(7), 13321340 .

83 R. E. Sturgeon and P. Grinberg, J. Anal. At. Spectrom., 2012, 27(2), 222-231.

84 X. L. Hou, X. Ai, X. M. Jiang, P. C. Deng, C. B. Zheng and Y. Lv, Analyst, 2012, 137(3), 686-690.

85 C. S. Da Silva, E. Q. Oreste, A. M. Nunes, M. A. Vieira and A. S. Ribeiro, J. Anal. At. Spectrom., 2012, 27(4), 689-694.

86 H. Matusiewicz and E. Stanisz, J. Braz. Chem. Soc., 2012, 23(2), 247-257.

87 H. M. Li, Y. C. Luo, Z. X. Li, L. M. Yang and Q. Q. Wang, Anal. Chem., 2012, 84(6), 2974-2981.

88 J. A. Nobrega, R. E. Sturgeon, P. Grinberg, G. J. Gardner, C. S. Brophy and E. E. Garcia, J. Anal. At. Spectrom., 2011, 26(12), 2519-2523.

89 Z. F. Liu, Z. L. Zhu, Q. J. Wu, S. H. Hu and H. T. Zheng, Analyst, 2011, 136(21), 4539-4544.

90 J. Hassler, P. Barth, S. Richter and R. Matschat, J. Anal. At. Spectrom., 2011, 26(12), 2404-2418.

$91 \quad$ N. Becker and T. Wirtz, Anal. Chem., 2012, 84(14), 5920-5924. 
92 Y. Kohara, Y. Terui, M. Ichikawa, T. Shirasaki, K. Yamamoto, T. Yamamoto and Y. Takamura, J. Anal. At. Spectrom., 2012, 27(9), 1457-1464.

93 S. K. Fan, Y. T. Shen, L. P. Tsai, C. C. Hsu, F. H. Ko and Y. T. Cheng, LChip, 2012, 12(19), 3694-3699.

94 Q. He, Z. L. Zhu, S. H. Hu, H. T. Zheng and L. L. Jin, Anal. Chem., 2012, 84(9), 4179-4184.

95 M. Ponta, M. Frentiu and T. Frentiu, Acta Chim. Slov., 2012, 59(2), 359-365.

96 T. Frentiu, M. Ponta, E. Darvasi, M. Frentiu and E. Cordos, Food Chem., 2012, 134(4), 2447-2452.

97 K. Jankowski, A. P. Ramsza, E. Reszke and A. Tyburska, J. Anal. At. Spectrom., 2012, 27(8), 1287-1293.

98 K. F. von Reden, M. L. Roberts, J. R. Burton and S. R. Beaupre, RScI, 2012, 82(2), 4.

99 F. X. Xu, L. Wang, C. Luo and C. F. Ding, Chin. J. Anal. Chem., 2011, 39(10), 1501-1505.

100 G. Lotito and D. Gunther, Anal. Bioanal. Chem., 2012, 402(8), 2565-2576.

101 Y. Ikeda and R. Tsuruoka, ApOpt, 2012, 51(7), B183-B191.

102 V. A. Labusov, V. G. Garanin and I. R. Shelpakova, J. Anal. Chem., 2012, 67(7), 632-641.

103 O. Hadjar, T. Schlatholter, S. Davila, S. A. Catledge, K. Kuhn, S. Kassan, G. Kibelka, C. Cameron and G. F. Verbeck, J. Am. Soc. Mass Spectrom., 2011, 22(10), 1872-1884.

104 P. Collon, M. Bowers, F. Calaprice, C. Galbiati, D. Henderson, T. Hohman, C. L. Jiang, W. Kutschera, H. Y. Lee, B. Loer, R. C. Pardo, M. Paul, E. Rehm, D. Robertson, C. Schmitt, R. Scott and R. Vondrasek, Nuclear Instruments \& Methods in Physics Research Section B-Beam Interactions with Materials and Atoms, 2012, 283(77-83.

105 H. Lee, C. Oh and J. W. Hahn, Propellants Explosives Pyrotechnics, 2012, 37(1), 116-121.

106 A. Marinov, A. Pape, Y. Kashiv, D. Kolb, L. Halicz, I. Segal and R. Brandt, Int. J. Mod. Phys. E-Nucl. Phys., 2011, 20(11), 2403-2406.

107 P. Ludwig, T. Faestermann, G. Korschinek, G. Rugel, I. Dillmann, L. Fimiani, S. Bishop and P. Kumar, PhRvC, 2012, 85(2), 8.

108 S. Civis, M. Ferus, P. Kubelik, P. Jelinek, V. E. Chernov and E. M. Zanozina, Astronomy \& Astrophysics, 2012, 542(10.

109 L. Novosad, A. Hrdlicka, P. Slavicek, V. Otruba and V. Kanicky, J. Anal. At. Spectrom., 2012, 27(2), 305-309.

110 J. R. Dettman and J. W. Olesik, J. Anal. At. Spectrom., 2012, 27(4), 581-594.

111 H. Wiltsche, F. Moradi and G. Knapp, Spectrochim. Acta Pt. B-Atom. Spectrosc., 2012, 71-72(48-53.

112 S. M. McIntyre, J. W. Ferguson and R. S. Houk, Spectrochim. Acta Pt. B-Atom. Spectrosc., 2011, 66(8), 581-587.

113 C. Agatemor and D. Beauchemin, Anal. Chim. Acta, 2011, 706(1), 66-83.

114 M. Aghaei, H. Lindner and A. Bogaerts, J. Anal. At. Spectrom., 2012, 27(4), 604-610. 
115 L. Flamigni, J. Koch, H. Wiltsche, R. Brogioli, S. Gschwind and D. Gunther, J. Anal. At. Spectrom., 2012, 27(4), 619-625.

116 A. Murtazin, S. Groh and K. Niemax, Spectrochim. Acta Pt. B-Atom. Spectrosc., 2012, 67(3-16.

117 R. S. Amais, G. L. Donati and J. A. Nobrega, Anal. Chim. Acta, 2011, 706(2), 223-228.

118 G. L. Donati, R. S. Amais and J. A. Nobrega, J. Anal. At. Spectrom., 2012, 27(8), 1274-1279.

119 H. J. Heinrich and H. Kipphardt, Spectrochim. Acta Pt. B-Atom. Spectrosc., 2012, 70(68-73.

120 M. D. Huang, H. Becker-Ross, M. Okruss, S. Geisler and S. Florek, J. Anal. At. Spectrom., 2012, 27(6), 982-988.

121 V. N. Oreshkin and G. I. Tsizin, J. Anal. Chem., 2011, 66(10), 951-954.

122 J. O. De Beer, C. Naert and E. Deconinck, Accredit. Qual. Assur., 2012, 17(3), 265-274.

123 S. Prikler and J. W. Einax, Anal. Bioanal. Chem., 2012, 403(9), 2563-2567.

124 S. Prikler, D. Pick and J. W. Einax, Anal. Bioanal. Chem., 2012, 403(4), 1109 1116.

125 Y. P. Wang, Q. Gong, S. R. Yu and Y. Y. Liu, Spectrosc. Spectr. Anal., 2012, 32(4), 1098-1102.

126 D. W. Hahn and N. Omenetto, ApSpe, 2012, 66(4), 347-419.

127 A. K. Pathak, R. Kumar, V. K. Singh, R. Agrawal, S. Rai and A. K. Rai, ApSRv, 2012, 47(1), 14-40.

128 R. C. Chinni, J. Chem. Educ., 2012, 89(5), 678-680.

129 H. Y. Moon, B. W. Smith and N. Omenetto, ChPh, 2012, 398(221-227.

130 L. Zimmer and S. Yoshida, ExFl, 2012, 52(4), 891-904.

131 S. H. Zhang, X. L. Yu, F. Li, G. J. Kang, L. H. Chen and X. Y. Zhang, OptLE, 2012, 50(6), 877-882.

132 M. Banaee and S. H. Tavassoli, Polym. Test., 2012, 31(6), 759-764.

133 F. C. De Lucia and J. L. Gottfried, ApOpt, 2012, 51(7), B83-B92.

134 M. D. Dyar, M. L. Carmosino, E. A. Breves, M. V. Ozanne, S. M. Clegg and R. C. Wiens, Spectrochim. Acta Pt. B-Atom. Spectrosc., 2012, 70(51-67.

135 P. Yaroshchyk, D. L. Death and S. J. Spencer, J. Anal. At. Spectrom., 2012, 27(1), 92-98.

136 J. J. Hatch, T. R. McJunkin, C. Hanson and J. R. Scott, ApOpt, 2012, 51(7), B155-B164.

137 A. M. Matiaske, I. B. Gornushkin and U. Panne, Anal. Bioanal. Chem., 2012, 402(8), 2597-2606.

138 D. A. Cremers, A. Beddingfield, R. Smithwick, R. C. Chinni, C. R. Jones, B. Beardsley and L. Karch, ApSpe, 2012, 66(3), 250-261.

139 F. B. Gonzaga and C. Pasquini, Spectrochim. Acta Pt. B-Atom. Spectrosc., 2012, 69(20-24.

140 D. Gagnon, S. Lessard, M. Verhaegen, P. Mutchmore, P. Bouchard, F. R. Doucet and M. Sabsabi, ApOpt, 2012, 51(7), B7-B12.

141 V. Zorba, J. Syzdek, X. L. Mao, R. E. Russo and R. Kostecki, ApPhL, 2012, $\mathbf{1 0 0}(23), 5$. 
142 S. Almaviva, L. Caneve, F. Colao, R. Fantoni and G. Maddaluno, J. Nucl. Mater., 2012, 421(1-3), 73-79.

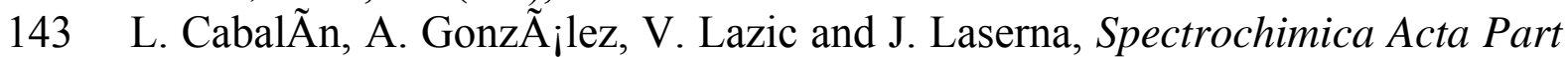
B: Atomic Spectroscopy, 2012.

144 P. G. Lucey, A. K. Misra and S. K. Sharma, Methods and apparatus for remote Raman and laser-induced breakdown spectrometry, 2012,

145 D. W. Hahn, Method and apparatus to laser ablation-laser induced breakdown spectroscopy, 2012,

146 D. R. Alexander, T. Anderson and I. J. C. Bruce, Laser Induced Breakdown Spectroscopy Having Enhanced Signal-to-Noise Ratio

2012,

147 A. A. Bol'shakov, X. Mao, C. P. McKay and R. E. Russo, presented at SPIE Defense, Security, and Sensing, 2012

148 Z. Q. Tan and X. W. Long, ApSpe, 2012, 66(5), 492-495.

149 C. J. Wang, P. Sahay and S. T. Scherrer, J. Anal. At. Spectrom., 2012, 27(2), 284-292.

150 E. Wagenaars, T. Gans, D. O'Connell and K. Niemi, Plasma Sources Science \& Technology, 2012, 21(4), 4.

151 W. D. Kulatilaka, J. R. Gord, V. R. Katta and S. Roy, Opt. Lett., 2012, 37(15), 3051-3053.

152 S. Ebata, M. Ishihara, K. Uchino, S. Itose, M. Matsuya, M. Kudo, K. Bajo and H. Yurimoto, SurIA, 2012, 44(6), 635-640.

153 K. Newman, J. Anal. At. Spectrom., 2012, 27(1), 63-70.

154 K. Newman and R. B. Georg, ChGeo, 2012, 304(151-157.

155 K. Heister, C. Hoschen, G. J. Pronk, C. W. Mueller and I. Kogel-Knabner, J. Soils Sed., 2012, 12(1), 35-47.

156 P. J. Hatton, L. Remusat, B. Zeller and D. Derrien, Rapid Commun. Mass Spectrom., 2012, 26(11), 1363-1371.

157 M. Schiller, C. Paton and M. Bizzarro, J. Anal. At. Spectrom., 2012, 27(1), 3849.

158 K. Mathew, P. Mason, A. Voeks and U. Narayanan, Int. J. Mass spectrom., 2012, 315(8-14.

159 E. Gautier, R. Garavaglia, A. Lobo, M. Fernandez and H. Farach, J. Anal. At. Spectrom., 2012, 27(5), 881-883.

160 M. Touboul and R. J. Walker, Int. J. Mass spectrom., 2012, 309(109-117.

161 O. Forstner, H. Gnaser, R. Golser, D. Hanstorp, M. Martschini, A. Priller, J. Rohlen, P. Steier, C. Vockenhuber and A. Wallner, Nuclear Instruments \& Methods in Physics Research Section B-Beam Interactions with Materials and Atoms, 2011, 269(24), 3180-3182.

162 J. Wang, T. X. Ren, H. Lu, T. Zhou and M. T. Zhao, Int. J. Mass spectrom., 2011, 308(1), 65-70.

163 N. N. Aruev and B. S. Boltenkov, Tech. Phys., 2012, 57(8), 1172-1177.

164 S. A. Crowther and J. D. Gilmour, J. Anal. At. Spectrom., 2012, 27(2), 256269.

165 T. M. Witte and R. S. Houk, Spectrochim. Acta Pt. B-Atom. Spectrosc., 2012, 69(9-19. 
166 B. Chapligin, H. Meyer, A. Bryan, J. Snyder and H. Kemnitz, ChGeo, 2012, 300(185-199.

167 P. S. Andersson and H. Schoberg, Limnol. Oceanogr. Meth., 2012, 10(296-303.

168 M. E. Auro, L. F. Robinson, A. Burke, L. I. Bradtmiller, M. Q. Fleisher and R. F. Anderson, Limnol. Oceanogr. Meth., 2012, 10(464-474.

169 C. Jeandel, C. Venchiarutti, M. Bourquin, C. Pradoux, F. Lacan, P. van Beek and J. Riotte, Geostand. Geoanal. Res., 2011, 35(4), 449-459.

170 J. W. Grate, M. J. O'Hara, A. F. Farawila, M. Douglas, M. M. Haney, S. L. Petersen, T. C. Maiti and C. L. Aardahl, Anal. Chem., 2011, 83(23), 90869091.

171 A. Marinov, A. Pape, D. Kolb, L. Halicz, I. Segal, N. Tepliakov and R. Brandt, Int. J. Mod. Phys. E-Nucl. Phys., 2011, 20(11), 2391-2401.

172 D. V. Biller and K. W. Bruland, Mar. Chem., 2012, 130(12-20.

173 T. Miyazaki, B. S. Vaglarov, M. Takei, M. Suzuki, H. Suzuki, K. Ohsawa, Q. Chang, T. Takahashi, Y. Hirahara, T. Hanyu, J. I. Kimura and Y. Tatsumi, J. Mineral. Petrol. Sci., 2012, 107(2), 74-86.

174 L. Gall, H. Williams, C. Siebert and A. Halliday, J. Anal. At. Spectrom., 2012, 27(1), 137-145.

175 M. A. Millet, J. A. Baker and C. E. Payne, ChGeo, 2012, 304(18-25.

176 O. Y. Ghidan and R. D. Loss, Int. J. Mass spectrom., 2012, 309(79-87.

177 S. Garcia-Ruiz, I. Petrov, E. Vassileva and C. R. Quetel, Anal. Bioanal. Chem., 2011, 401(9), 2785-2792.

178 S. Burger, S. D. Balsley, S. Baumann, J. Berger, S. F. Boulyga, J. A. Cunningham, S. Kappel, A. Koepf and J. Poths, Int. J. Mass spectrom., 2012, 311(40-50.

179 T. Shinonaga, D. Donohue, H. Aigner, S. Burger, D. Klose, T. Karkela, R. Zilliacus, A. Auvinen, O. Marie and F. Pointurier, Anal. Chem., 2012, 84(6), 2638-2646.

180 F. Esaka, C. G. Lee, M. Magara and T. Kimura, Anal. Chim. Acta, 2012, 721(122-128.

181 F. Pointurier, A. C. Pottin and A. Hubert, Anal. Chem., 2011, 83(20), 78417848.

182 A. Huber, B. Schweer, V. Philipps, N. Gierse, M. Zlobinski, S. Brezinsek, W. Biel, V. Kotov, R. Leyte-Gonzales, P. Mertens and U. Samm, Fusion Eng. Des., 2011, 86(6-8), 1336-1340.

183 Y. Nedjadi, C. Bailat, Y. Caffari, P. Froidevaux, C. Wastiel, N. Kivel, I. Guenther-Leopold, G. Triscone, F. Jaquenod and F. Bochud, Appl. Radiat. Isot., 2012, 70(9), 1990-1996.

184 G. Z. He, S. Jiang, Z. Y. Zhou, M. He, W. Z. Tian, J. L. Zhang, L. J. Diao and H. Li, PhRvC, 2012, 86(1), 5.

185 G. Jorg, Y. Amelin, K. Kossert and C. L. von Gostomski, Geochim. Cosmochim. Acta, 2012, 88(51-65.

186 E. Rotenberg, D. W. Davis, Y. Amelin, S. Ghosh and B. A. Bergquist, Geochim. Cosmochim. Acta, 2012, 85(41-57.

187 C. Paton, M. Schiller, D. Ulfbeck and M. Bizzarro, J. Anal. At. Spectrom., 2012, 27(4), 644-652. 
188 J. A. Baker, M. Schiller and M. Bizzarro, Geochim. Cosmochim. Acta, 2012, 77(415-431.

189 M. Bizzarro, J. N. Connelly, K. Thrane and L. E. Borg, Geochemistry Geophysics Geosystems, 2012, 13(10.

190 N. Brickel, P. Gandhi, K. VanLandingham, J. Hammond and S. DeRossett, Epilepsia, 2012, 53(4), 606-612.

191 Z. Y. Chu, J. H. Guo, Y. H. Yang, L. Qi, L. Chen, X. C. Li and J. F. Gao, J. Anal. At. Spectrom., 2012, 27(3), 509-515.

192 R. Taylor, C. Clark and S. M. Reddy, ChGeo, 2012, 300(81-87.

193 R. Escoube, O. J. Rouxel, B. Luais, E. Ponzevera and O. F. X. Donard, Geostand. Geoanal. Res., 2012, 36(2), 149-159.

194 A. Bernstein, O. Shouakar-Stash, K. Ebert, C. Laskov, D. Hunkeler, S. Jeannottat, K. Sakaguchi-Soder, J. Laaks, M. A. Jochmann, S. Cretnik, J. Jager, S. B. Haderlein, T. C. Schmidt, R. Aravena and M. Elsner, Anal. Chem., 2011, 83(20), 7624-7634.

195 J. Vogl and M. Rosner, Geostand. Geoanal. Res., 2012, 36(2), 161-175.

196 K. Moeller, R. Schoenberg, R. B. Pedersen, D. Weiss and S. F. Dong, Geostand. Geoanal. Res., 2012, 36(2), 177-199.

197 K. Jaouen, V. Balter, E. Herrscher, A. Lamboux, P. Telouk and F. Albarede, Am. J. Phys. Anthropol., 2012, 148(3), 334-340.

198 H. W. Kreuzer, J. Horita, J. J. Moran, B. A. Tomkins, D. B. Janszen and A. Carman, J. Forensic Sci., 2012, 57(1), 75-79.

199 M. X. Ling, F. Sedaghatpour, F. Z. Teng, P. D. Hays, J. Strauss and W. D. Sun, Rapid Commun. Mass Spectrom., 2011, 25(19), 2828-2836.

200 R. I. Gabitov, E. B. Watson and A. Sadekov, ChGeo, 2012, 306(92-102.

201 C. Brahmi, I. Domart-Coulon, L. Rougee, D. G. Pyle, J. Stolarski, J. J. Mahoney, R. H. Richmond, G. K. Ostrander and A. Meibom, Coral Reefs, 2012, 31(3), 741-752.

202 B. Paul, C. Paton, A. Norris, J. Woodhead, J. Hellstrom, J. Hergt and A. Greig, J. Anal. At. Spectrom., 2012, 27(4), 700-706.

203 K. W. McMahon, M. L. Berumen, I. Mateo, T. S. Elsdon and S. R. Thorrold, Coral Reefs, 2011, 30(4), 1135-1145.

204 K. W. McMahon, M. L. Fogel, B. J. Johnson, L. A. Houghton and S. R. Thorrold, Can. J. Fish. Aquat. Sci., 2011, 68(8), 1330-1340.

205 K. Ariyama, M. Shinozaki and A. Kawasaki, J. Agric. Food Chem., 2012, 60(7), 1628-1634. 